\title{
Coal-mining intensity influences species and trait distributions of stream fishes in two Central Appalachian watersheds
}

\author{
Zachary P. Martin ${ }^{1}$ (D) | Paul L. Angermeier ${ }^{1,2}$ (D) $\mid$ Serena Ciparis ${ }^{1,3}$ | Donald J. Orth
}

${ }^{1}$ Department of Fish and Wildlife Conservation, Virginia Polytechnic Institute and State University, Blacksburg, VA, USA

${ }^{2}$ U.S. Geological Survey, Virginia Cooperative Fish and Wildlife Research Unit, Virginia Polytechnic Institute and State University, Blacksburg, VA, USA

${ }^{3}$ U.S. Fish and Wildlife Service, Virginia Field Office, Gloucester, VA, USA

Correspondence

Zachary P. Martin, Cheatham Hall, 310 West Campus Drive, Blacksburg, VA 24061, USA.

Email: zpmartin@vt.edu

Funding information

Virginia Center for Coal and Energy

Research, Appalachian Research Institute for Environmental Science, Grant/Award Number: 000900

\begin{abstract}
Documenting responses of biotic assemblages to coal-mining impacts is crucial to informing regulatory and reclamation actions. However, attributing biotic patterns to specific stressors is difficult given the dearth of preimpact studies and prevalence of confounding factors. Analysing species distributions and abundances, especially stratified by species traits, provides insights into how assemblage composition shifts occur. We evaluated stream habitats and fish assemblages along a mining intensity gradient in 83 headwater (2nd- and 3rd-order) streams of the upper Clinch and Powell river basins in Virginia. Our multivariate gradient (MINE.PC1) was based on percentages of watershed area covered by surface mine, underground mine and valley fill to represent spatial variance in mining intensity. MINE.PC1 was positively correlated with conductivity and percentage of substrate as cobble. Forty fish-assemblage metrics were analysed via boosted regression trees to assess assemblage responses to mining intensity, while accounting for environmental variation and spatial structure among sites. Conductivity and MINE.PC1 were strongly negatively related to occurrences of Fantail Darter (Etheostoma flabellare) and sculpin (Cottus) spp. Several taxonomic, trophic and reproductive metrics of assemblage composition responded strongly to mining intensity or its instream correlates. For example, coal mining favoured omnivore-herbivores, but inhibited invertivores, simple lithophils and nonsimple nonlithophils. We revealed distinct negative and positive responses to mining-related stressors, which suggest changes to macroinvertebrate prey availability and/or contaminant loads contribute to fish extirpations in coalfield streams. Future assessments of mining impacts on fish assemblages could be more instructive by including characterisations of physicochemical stressors and regionally calibrated biotic metrics with demonstrated sensitivity to mining.
\end{abstract}

KEYWORDS

assemblage structure, bioassessment, boosted regression trees, coal-mining gradient, mining impacts, species traits 


\section{1 | INTRODUCTION}

Coal mining profoundly impacts the physical, chemical and biological character of $>1,900 \mathrm{~km}$ of headwater streams in Appalachia (USEPA, 2005), a region in eastern USA containing highly diverse aquatic ecosystems regarded as global conservation priorities (Giam et al., 2018; Smith et al., 2002). For example, current biotic stream assemblages in the upper Tennessee River basin are decimated relative to premining assemblages (Giam et al., 2018). Key coal-mining threats to aquatic biota include toxic point-source discharges, nonpoint-source pollution and coal-waste disposal (USEPA, 2002). Alterations to water and habitat quality in coalfield streams result in multiple synergistic stressors that lead to numerically and functionally depauperate fish assemblages via multiple pathways (Daniel et al., 2015; Giam et al., 2018; Hitt \& Chambers, 2014; Hopkins \& Roush, 2013; Schorr \& Backer, 2006). Although reclamation standards and proposed water-quality criteria aim to protect aquatic life (USEPA, 2016a, 2016b), much uncertainty remains regarding how to mitigate effectively the landscape-scale impacts of coal mining on stream biota (Bernhardt \& Palmer, 2011). Improving mitigation policy and approaches requires understanding of links among mining activity, watershed processes, instream conditions, biotic fitness measures and population responses.

Potential impacts of coal mining on stream fishes follow a hierarchy of linkages which we illustrate with a conceptual model (Figure 1), passing from landscape features to instream conditions to assemblage composition. Overt manipulations of topography, geology and land cover on surface-mined lands can modify a host of ecological processes, including surface-water runoff and infiltration, geologic weathering, sediment transport and deposition and biological production (Ross et al., 2016; Touysinhthiphonexay \& Gardner, 1984; Zipper et al., 2011). Underground mining may alter hydrologic processes via sinks and seeps (USGS, 2000). Consequently, the delivery of fine sediments, major ions, trace elements and metals to stream networks commonly increases in mined landscapes.

Our conceptual model traces the many potential biotic outcomes of these inputs through three broad pathways that include physical habitat, water chemistry and/or food resources. Stream habitats downstream of mines commonly exhibit excess fine sediment-or burial in the case of valley fills (Griffith et al., 2012; Nuttle et al., 2017), elevated water temperatures (USGS, 2001) and increased insolation (Bernhardt \& Palmer, 2011). Water chemistry downstream of surface and underground mines in the Appalachian coalfield commonly shows elevated concentrations of total dissolved solids (TDS) and associated measurements of conductivity (Cormier, Wilkes, et al., 2013; Evans et al., 2014; Griffith et al., 2012; Nippgen et al., 2017; Petty et al., 2010; Zipper et al., 2016). Elevated concentrations of selenium (Se) have also been documented (Griffith et al., 2012; Pond et al., 2008; Ross et al., 2016). Effects of coal mining on food resources for fishes include decreased allochthonous inputs (e.g., leaves, macroinvertebrates) and increased autochthonous production (Bernhardt \& Palmer, 2011; Drover et al., 2020; USFS, 2017). Mining effects on physical habitat and water chemistry are linked to food resources via bioaccumulation of contaminants (e.g., Se) and shifts in food availability (Arnold et al., 2014; Presser, 2013).

Changes in instream conditions affect fitness (e.g., survival, growth, reproduction) of individual fish through many potential modes of action, such as development, metabolism, behaviour and disease (USEPA, 2016b). Fitness outcomes of mining-related shifts in water quality are most extensively documented, including elevated TDS causing egg and fry mortality (Weber-Scannell \& Duffy, 2006) and elevated Se impairing development (Arnold et al., 2014; Holm et al., 2003) in mined watersheds. Retrospective investigations of species' intolerance to elevated conductivity (e.g., sculpins and darters) provide a platform for synthesising general expectations for population- and community-level mining impacts (Griffith et al., 2018; Hitt et al., 2016; Hopkins \& Roush, 2013; USEPA, 2016b). However, in most cases specific mechanisms of toxicity, and ultimately extirpation, are not understood. Pathways connecting fitness and mining impacts on physical habitat may involve restricted access to foraging, spawning and/or refuge spaces (Kemp et al., 2011; MacDonald \& McDonald, 1987). Indirect effects of mining-related shifts in food availability or contamination may reduce stream-fish fitness (Arnold et al., 2014; Hitt \& Chambers, 2014; Presser \& Luoma, 2010), yet the relative importance of food contamination versus availability remains unclear. Overall, sublethal effects on fitness are rarely quantified and linked to population or assemblage outcomes (Presser, 2013; Presser \& Luoma, 2010). The prominence of retrospective inference and rarity of linking multiple levels of ecological organisation in investigations have contributed to critical knowledge gaps on the science on mining impact to stream ecosystems.

Many specific linkages and mechanisms implied in Figure 1 are poorly understood, especially as they may apply across Appalachia. Insights from previous studies of coal-mining impacts have been limited by (a) narrow foci on single species and/or stressors, (b) spatial designs confounded by nonmining land uses, or (c) spatiotemporal sampling designs that cannot account for within-region variance in mining intensity. Some studies of individual or population responses to instream stressors separately have described physiological mechanisms, organismal modes of action or fitness implications associated with mining impacts (Arnold et al., 2014; Ferreri et al., 2004; Hafs et al., 2010; Matter \& Ney, 1981; Schorr \& Backer, 2006; Stair et al., 1984), but these study designs have marginal replication across space, time and/or phylogeny. Interpretation of results from impact assessments is commonly confounded by mixed land uses in mined watersheds (Kimmel \& Argent, 2010; Schorr \& Backer, 2006). However, thoughtful study designs encompassing assemblages across suites of headwater catchments can advance our knowledge of mining impacts (Daniel et al., 2015; Giam et al., 2018; Hitt \& Chambers, 2014).

Trait-based approaches to assessing fish-assemblage responses to environmental gradients complement traditional taxonomic approaches (Frimpong \& Angermeier, 2010; Mouillot et al., 2013). Trait-based metrics commonly respond consistently across taxa and ecosystems, and can indicate impact before species are lost (Mouillot et al., 2013). Moreover, the variance in assemblage composition 


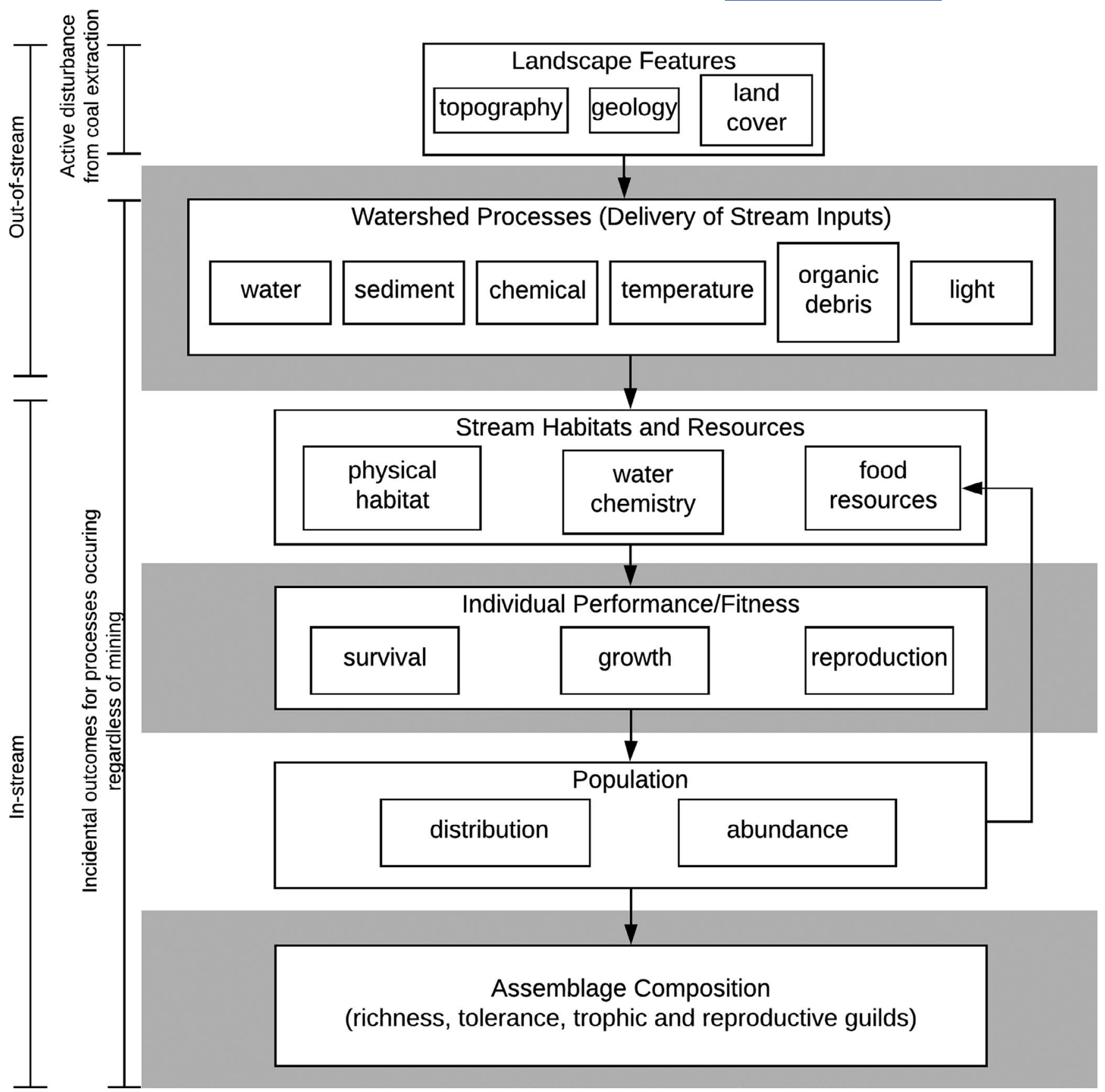

FIGURE 1 A simplified conceptual model of connections between landscape disturbance caused by coal mining and fish community assembly, guided by hypotheses posed by U. S. Environmental Protection Agency (USEPA, 2016b) and Norton and Schofield (2017). Arrows directions indicate potential influences. Coal mining dramatically alters landscape-level topography, geology and land cover, with consequences for the watershed processes that deliver inputs to streams. Changes in water quantity inputs (flow regime) are complex but often manifest as increased frequency and magnitude of floods. Magnitudes of sediment, chemicals, temperature and light generally increase with more mining, while organic debris (large wood, leaf litter and terrestrial macroinvertebrates) generally decreases. Outcomes for streams include changes to physical habitat (e.g., substrate composition), water chemistry (e.g., conductivity) and food resources (e.g., macroinvertebrates). Each of these has ties to individual performance (i.e., evolutionary fitness) as survival, growth, and reproduction via suites of physiological mechanisms and organismal modes of action. Shifts in individual performance affect population measures (i.e., distribution, abundance) and ultimately, community assembly

observed across headwaters may be best described by trait-based metrics (Colin et al., 2018). Few analyses of coal-mining impacts have adopted a trait-based approach (but see Daniel et al., 2015; Hitt \& Chambers, 2014). Indices of biotic integrity (IBIs), commonly used by states and other agencies to assess the ecological condition of streams based on their fish assemblages, typically include several trait-based metrics (e.g., proportional abundances of invertivores or simple lithophils). However, no fish-based IBI has been developed 
to primarily assess mining impacts. Given that effects of coal mining on stream fishes may be similar to certain effects of other anthropogenic alterations of landscapes (e.g., agriculture, urbanisation), it is reasonable to expect some currently used IBI metrics to be useful in detecting mining impacts. Previous studies suggest that trophic and reproductive compositions of fish assemblages often shift in systems affected by surface mining (Cormier, Suter, et al., 2013; Cormier, Wilkes, et al., 2013; Daniel et al., 2015; Hitt \& Chambers, 2014; Northington et al., 2011; Pond et al., 2008). Other IBI metrics describing taxonomic diversity (e.g., richness) and tolerance (e.g., general or mining-specific) may also detect effects of mining but need formal evaluation and comparison. Assemblage-level analyses of species traits may help clarify the links among mining activities, related physicochemical alterations to streams and consequent changes in fish distributions and abundances.

We evaluated the responses of stream habitats and fish assemblages to coal mining across a gradient of mining influence in headwater streams of the upper Clinch and Powell river basins in Southwest Virginia. Headwater streams were chosen to isolate mining effects and minimise confounding, cumulative effects of other anthropogenic activities in watersheds. Our study objectives are to (a) characterise instream physicochemical responses to mining intensity in terms of water quality and physical habitat, (b) characterise fish responses to mining intensity in terms of shifts in species distribution and assemblage composition, and (c) synthesise results on interactions among mining intensity, physicochemical conditions and assemblage composition to fill gaps in the conceptual model(s) of coal mining impacts on stream fishes. We expected (a) conductivity and fine sedimentation to increase with increasing mining intensity, (b) species richness to decrease with increasing mining intensity, (c) assuming expectations from (a) are met, subsequent decreases in occurrence and proportional abundance of species sensitive to conductivity and sedimentation (e.g., sculpins and darters) and (d) proportional abundances of trophic (e.g., invertivores) and reproductive (e.g., simple lithophils) guilds to shift with physicochemical changes known to affect food and habitat resources.

\section{2 | MATERIALS AND METHODS}

\section{1 | Study area}

Our study extent comprised the upper Clinch River (06010205) and Powell River (06010206) 8-digit hydrologic units (HUC8s) of the Tennessee River basin in Virginia (McKay et al., 2012) (Figure 2). The confluence of the Clinch and Powell rivers is located at Norris Lake, TN. These rivers are located within the Valley and Ridge and the Appalachian Plateau physiographic provinces and contain similar fish assemblages (Angermeier \& Winston, 1999). These HUC8s are high priorities for freshwater conservation in the U.S. based on richness and endemism of fishes, crayfishes and mussels (Smith et al., 2002; Elkins et al., 2019). Coal mining in these drainages, largely restricted to the Appalachian Plateau, includes underground mining, surface mining, and valley fill operations (VDMME, 2015). While much of the

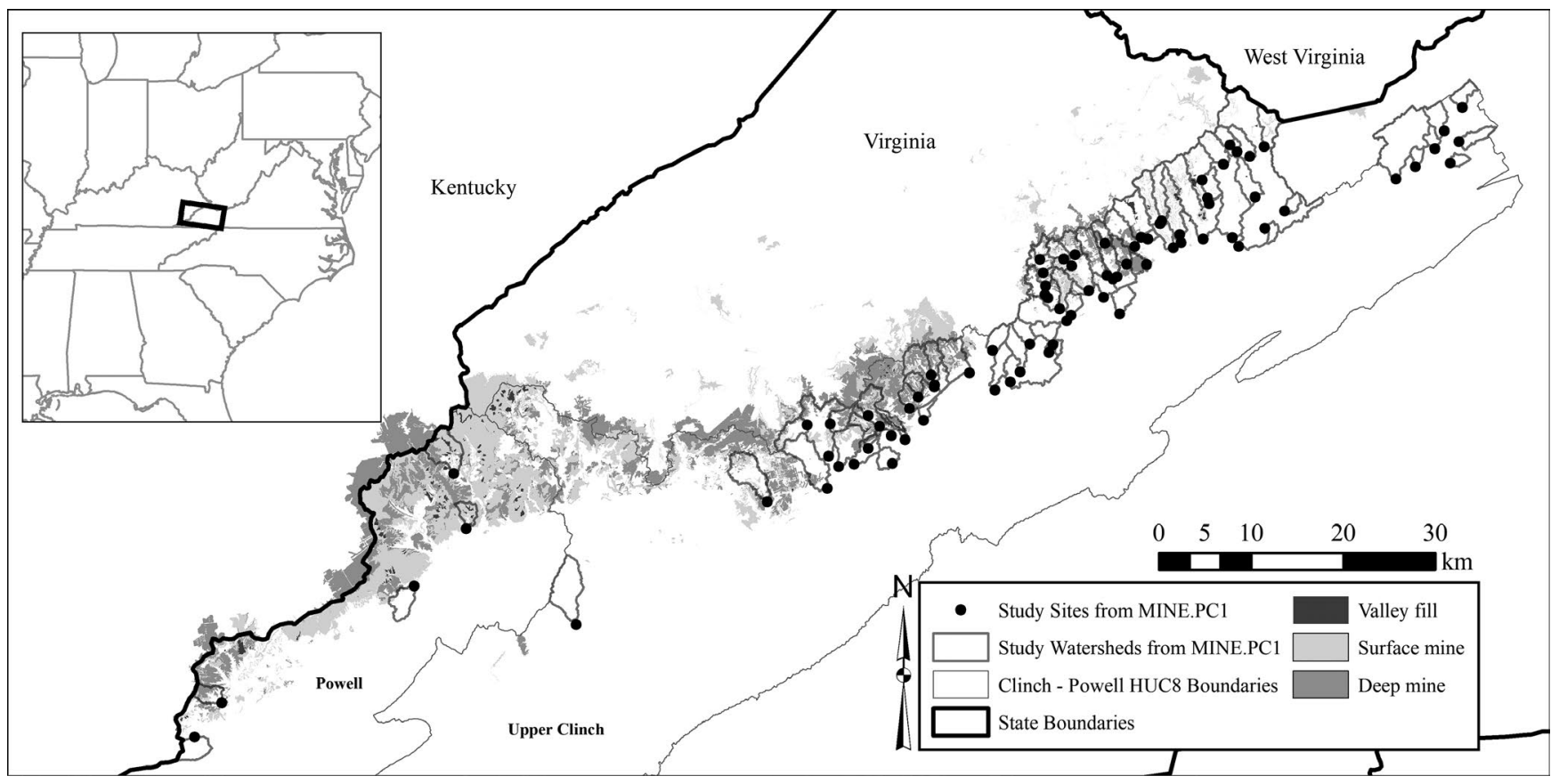

FIGURE 2 Map of the study extent, sites (black dots) and their watersheds ( $n=83$; light grey boundaries) for which data on fish assemblage, physical habitat, water quality and watershed characteristics were compiled. The study extent includes the portions of the 8-digit hydrologic units (HUC8s) of the upper Powell River and upper Clinch River (dark grey boundaries) contained within the coalfields of south-western Virginia. Classes of mining extent included active surface mine (light grey fill), active deep mine (grey fill) and valley fill (dark grey fill). Mining intensity among watersheds based on these three classes was characterised with principal component analysis (PCA) and the first principal components (MINE.PC1) served as our multivariate gradient of mining intensity 
TABLE 1 Summary of underground ("deep") mining, surface mining and valley fill extents within the 83 study watersheds, their pairwise Pearson's correlation coefficients, and the principal components $(\mathrm{PC})$ analysis

\begin{tabular}{|c|c|c|c|c|c|c|}
\hline & \multicolumn{2}{|c|}{ Deep mining } & \multicolumn{2}{|c|}{ Surface mining } & \multicolumn{2}{|c|}{ Valley fill } \\
\hline & $\left(\mathrm{km}^{2}\right)$ & $\%$ & $\left(\mathrm{~km}^{2}\right)$ & $\%$ & $\left(\mathrm{~km}^{2}\right)$ & $\%$ \\
\hline \multicolumn{7}{|c|}{ Summary statistics } \\
\hline Min & 0.00 & 0.00 & 0.00 & 0.00 & 0.00 & 0.00 \\
\hline Max & 17.39 & 78.64 & 7.78 & 87.98 & 1.02 & 24.27 \\
\hline Mean & 1.86 & 20.32 & 1.18 & 11.97 & 0.07 & 0.88 \\
\hline \multicolumn{7}{|c|}{ Pearson's correlation coefficients } \\
\hline \multicolumn{7}{|c|}{ Deep $\left(\mathrm{km}^{2}\right)$} \\
\hline Deep (\%) & 0.85 & & & & & \\
\hline $\begin{array}{c}\text { Surface } \\
\left(\mathrm{km}^{2}\right)\end{array}$ & 0.72 & 0.51 & & & & \\
\hline $\begin{array}{l}\text { Surface } \\
(\%)\end{array}$ & 0.58 & 0.62 & 0.85 & & & \\
\hline Fill $\left(\mathrm{km}^{2}\right)$ & 0.28 & 0.20 & 0.54 & 0.47 & & \\
\hline Fill (\%) & 0.21 & 0.24 & 0.42 & 0.48 & 0.91 & \\
\hline \multicolumn{7}{|l|}{ PC loadings } \\
\hline $\begin{array}{l}\text { PC1 } \\
(64 \%)\end{array}$ & - & 0.58 & - & 0.65 & - & 0.49 \\
\hline $\begin{array}{l}\text { PC2 } \\
(26 \%)\end{array}$ & - & 0.58 & - & & - & -0.81 \\
\hline $\begin{array}{l}\text { PC3 } \\
(10 \%)\end{array}$ & - & 0.57 & - & -0.75 & - & 0.33 \\
\hline
\end{tabular}

Note: Summary statistics and correlations for both measured area $\left(\mathrm{km}^{2}\right)$ and percentage (\%) of watershed areas. Variable loadings on the three PCs for the mining extents as percentage watershed area are presented at the bottom of the table. Percentages next to the PC labels (PC1, PC2, PC3) are the percent of variance explained. Blank cells indicate (a) redundant pairwise relationships in the correlation matrix, and (b) PC variable loading was below 0.1. Dashes indicate the measured area variables were not included in the PCA.

region has been intensely mined over the past four decades, some coal-bearing areas remain forested and unmined (VDMME, 2015; Zipper et al., 2016). This spatial variance, as well as high historical fish diversity, makes these drainages well-suited for examining physicochemical conditions and assemblage composition among headwater watersheds along a mining-intensity gradient.

\subsection{Site selection and mining-intensity gradient}

We used existing data to construct a mining-intensity gradient and choose representative sites. Known fish and habitat sampling localities from state and federal agencies, and researchers at Virginia Tech, were overlaid on our study area with geospatial layers of stream networks and topography from the National Hydrography Dataset Plus Version 2 (NHDPlusV2), and coal mining permits and features (Martin et al., 2018; Moore et al., 2017; Timpano et al., 2015). All geospatial analyses were conducted in ArcMap 10.3
(ESRI, Inc., Redlands, CA). Geospatial data on the areal extents (e.g., $\mathrm{km}^{2}$ ) of active surface-mine permits, active deep-mine permits and valley fills (pre- and postbond release) were obtained from Virginia Department of Mines, Minerals, and Energy, Division of Mined Land Reclamation (VDMME, 2015) (Figure 2). Sites and NHDPlusV2 flowlines were assigned a Strahler stream order according to NHDPlusV2 FlowlineVAA table data (McKay et al., 2012). Our candidate headwater (i.e., 2nd- and 3rd-order) streams included all flowlines at least two fluvial kilometres upstream of mainstem flowlines (i.e., $\geq 5$ th-order). We focused on headwaters to isolate mining effects and minimise confounding, cumulative watershed effects. Ultimately, the 83 selected sites represented watersheds of varying intensities of mining-related disturbance throughout our study area. Our samples drew from data collected in a separate study during the summer and fall of 2014 and 2015 (Moore et al., 2017), plus data we collected in summer and fall of 2015 (Martin et al., 2018).

Watershed characteristics upstream of these 83 sites were used to develop a multivariate mining-intensity gradient from a principal components analysis (PCA) to represent the many environmental factors associated with mining across complex landscapes. Percentage areas of surface mine, deep mine and valley fill extents from the 83 watersheds were used to characterise mining intensity; sites were located at pour points, as delineated in the 30-m NHDPlusV2 digital elevation model (McKay et al., 2012). Strong spatial overlap among the three classes of mining precluded us from examining their influences separately. In particular, deep mines commonly underlie surface mines and valley fills. The PCA was performed in the R statistical program using the princomp function in the stats package $(R$ Core Team, 2018, Vienna, Austria). The first principal component (PC1; see Table 1) represented $64 \%$ of the variance in mining activity across sites, and all three mining variables loaded heavily and positively on this component (Figure 2). PC1 served as our multivariate gradient of mining intensity in subsequent analyses and is hereafter referred to as MINE.PC1.

\section{3 | Environmental variables from field surveys}

The merged physical habitat databases included variables from two field surveys (Martin et al., 2018; Moore et al., 2017). Both data sets included site-scale channel morphology, substrate characteristics and water chemistry sampled by adapting U.S. Geological Survey National Water-Quality Assessment (Fitzpatrick et al., 1998) and U.S. Forest Service (Bunte \& Abt, 2001) protocols to characterise the variance in physicochemical habitat among watersheds. Instream conditions were sampled within a set fluvial length of stream (i.e., a reach) which represented each site. Survey protocols between the studies were similar, with a few notable differences. For instance, the total fluvial length of reaches for physical habitat and fish sampling measured $200 \mathrm{~m}$ (Moore et al., 2017) versus $250 \mathrm{~m}$ (Martin et al., 2018). We acknowledge variability in reach length can influence the observed means and measurement precision of habitat and fish assemblage attributes (Whitacre et al., 2007). However, 
both reach lengths were greater than or equal to lengths recommended in standard protocols to ensure representation of the range of physicochemical and biotic features present. Measures of channel morphology included wetted stream width, maximum depth and width-to-depth ratio at equidistantly spaced transects perpendicular to flow, plus the overall percentage of a site as run mesohabitat and the area sampled for fishes. Measures of substrate included visual estimates of percentages of coarse particles $\geq 75 \%$ embedded, bedrock, $\leq$ fine pebble ( $\leq 8 \mathrm{~mm}$ ), medium to coarse pebble (8-64 mm), cobble (64-256 mm) and boulder (256-4,096 mm). Substrate sizes noted above were particle diameters measured along the intermediate axis, or $b$-axis, during pebble counts. Measures of water chemistry included $\mathrm{pH}$ and conductivity $(\mu \mathrm{S} / \mathrm{cm})$ using the Hanna Phep 5 $\mathrm{pH}$ meter and Hanna HI98311 DiST ${ }^{\circledR} 5 \mathrm{EC} / \mathrm{TDS}$ meter, respectively, in one study (Moore et al., 2017), and the YSI EcoSense EC300A multi-meter in the second study (Martin et al., 2018). It is important to note that conductivity is used herein, and broadly elsewhere, as a surrogate measure for major ion concentration which is more directly related to biological effects (USEPA 2016b).

\section{4 | Environmental variables from geospatial analyses}

The watershed-scale topography, land cover and spatial-structure variables were derived from geospatial analyses. Elevation at the downstream reach boundary and channel slope (i.e., stream gradient) were determined using the NHDPlusV2 30-m digital elevation model (McKay et al., 2012). Watershed-scale predictors included watershed area (WSAREA), mining intensity (MINE.PC1) and three classes of forest cover. Percentages of watershed area as deciduous forest (DECFOREST), evergreen forest (EVFOREST) and mixed forest (MIXFOREST) from the 30-m 2011 National Land Cover Database (NLCD) served as potential predictors of fish species distributions (Hitt et al., 2016; Hopkins \& Roush, 2013). We examined Pearson's correlations during preliminary analyses between MINE.PC1 and the three forest cover classes to eliminate redundant and collinear variables, none of which were correlated. We assessed inherent spatial structure among our sites to account for spatial autocorrelation in our regression tree analyses (see Figure S1 and Accounting for spatial structure among study sites in Supplemental Materials). Including three spatial structure predictors (dbMEM1, dbMEM2, dbMEM3) in our regression tree models increased our confidence in our results on the influence of variables on patterns of species distribution and assemblage structure.

\section{5 | Fish assemblage data}

Fish assemblages were sampled at 83 sites, combining data from fish surveys in the summer and fall of 2014 and 2015 (Moore et al., 2017; $n=68$ ) with surveys in fall 2015 (Martin et al., 2018; $n=15$ ). Sampling dates ranged between 20 May and 7 October. We targeted baseflow conditions during fish and habitat sampling to maintain comparability among sites and years. Assemblages were sampled by crews moving upstream with a Smith-Root LR-24 backpack electrofisher and dipnets. Reaches were divided into 50-m subreaches. Two subreaches at each site were randomly selected, then elecrofished using singlepass methods. Single-pass backpack electrofishing typically catches $>70 \%$ of the total catch produced by three-pass methods and provides estimates of assemblage composition metrics (i.e., species richness, catch per effort) similar to three-pass methods (Stanfield et al., 2013). Thus, our single-pass protocol enabled us to adequately characterise assemblage composition while maximising sample size across the mining-intensity gradient. All captured fishes were identified to species and enumerated. Each of the 37 species captured was characterised at each site in terms of presence/absence (i.e., occurrence) and count (catch per effort). Prevalence of species among sites ranged from 0.01 to 0.95 (see Table S1, Supplemental Materials). Sculpins were pooled as Cottus spp., as four similar species (C. baileyi, C. bairdi, C. sp. cf. bairdi and C. carolinae) could not be distinguished reliably in the field.

\section{6 | Statistical analyses}

We performed analyses to (a) identify physicochemical correlates of MINE.PC1 that could serve as measurable indicators of habitat quality alteration along the mining gradient and (b) model the response of fish assemblage composition to mining-related predictors, after accounting for influences of other environmental factors. Assemblage composition responses were characterised by 40 metrics, grouped broadly as species occurrences and IBI component metrics (richness, proportional abundance, catch per effort). The IBI metrics came from existing Mid-Atlantic Highland IBIs (Angermeier et al., 2000; McCormick et al., 2001; TVA, 2005). The models included 23 predictor variables, which were compiled from our field survey data and geospatial analyses (Table 2).

The 23 predictors of assemblage composition included 15 sitescale variables, 5 watershed-scale variables, and the 3 spatial-structure variables noted above (Table 2). Predictor name abbreviations used hereafter are listed in Table 2. Site-scale predictors included physicochemical measures describing substrate composition, channel morphology and water chemistry. Watershed-scale predictors described watershed area (WSAREA), mining intensity (MINE.PC1) and forest cover. Lastly, the spatial-structure variables accounted for potential spatial autocorrelation resulting from the long east-west span of the study area.

Correlations among predictor variables were examined prior to modelling species distributions, especially in the interest of identifying physicochemical correlates of mining intensity (i.e., correlates of MINE.PC1). This analysis also provided more information on the potential for spatial structure bias in our fish assemblage response models. All statistical analyses were performed using $\mathrm{R}$ statistical software (R Core Team, 2018, Vienna, Austria). Pearson correlation coefficients (Pearson's $r$ ) were examined, and correlates 
TABLE 2 List of 23 predictor variables used in the boosted regression tree analysis

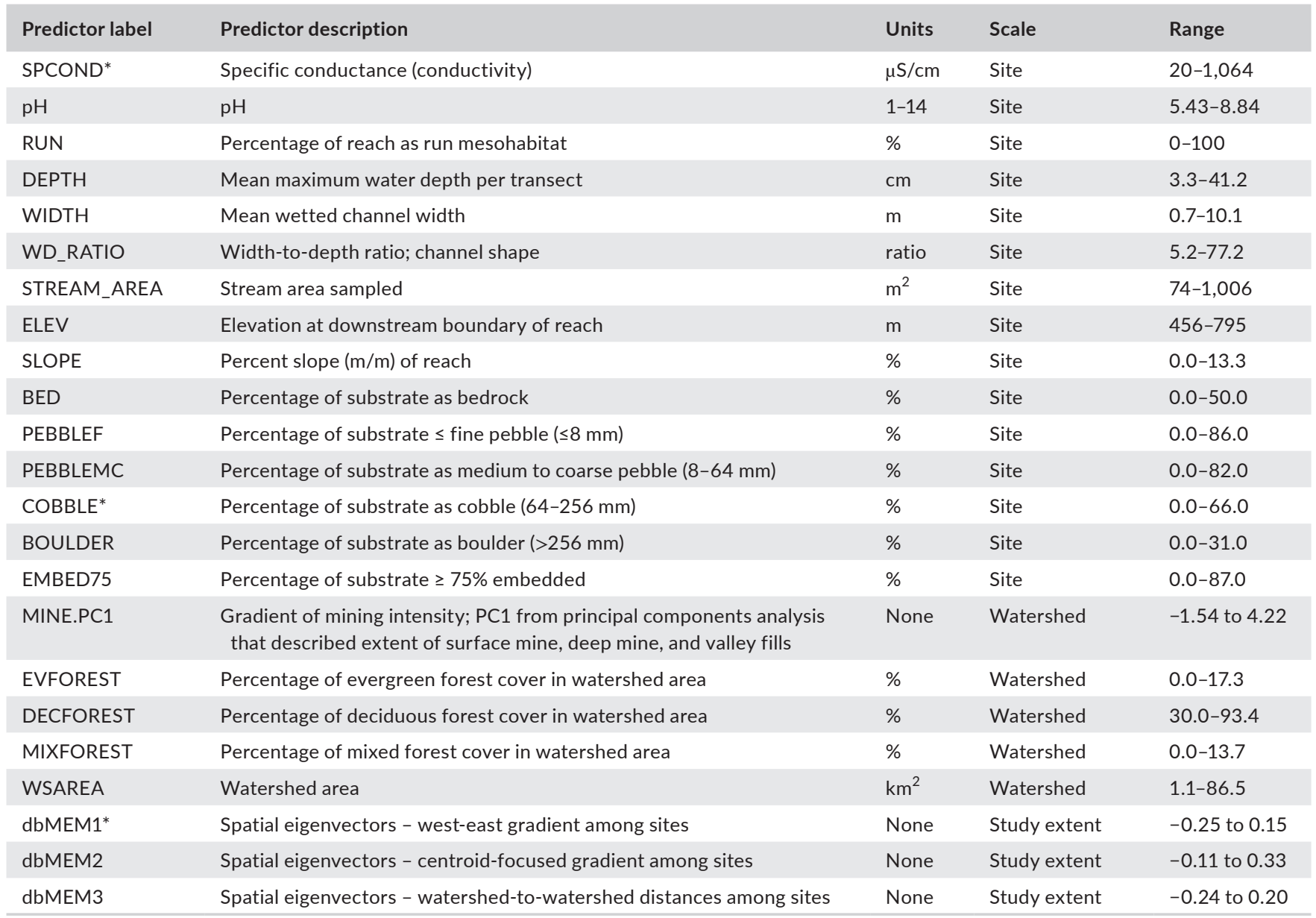

Note: Significant correlates $(\alpha=0.05 / 22)$ of MINE.PC1 are indicated with asterisks; each had $p<.005$.

were identified using a significance level of $\alpha=0.05$ with the simple Bonferroni correction for the number of predictors compared $(n=22)$. Predictors were either $\ln , \ln (x+1)$, or square-root transformed to approximate normality prior to the correlation analysis, except for MINE.PC1, pH, DECFOREST, and all three spatial structure eigenvalues.

Potential responses of fish assemblage composition were represented by nine measures of species occurrence and 31 IBI metrics (Table 3). The species occurrence measures characterised distributions of the nine most prevalent species (present at $\geq 17$ sites, or $\geq 0.20$ prevalence): Western Blacknose Dace (Rhinichthys obtusus, or "ROBT" hereafter) (0.95), Creek Chub (Semotilus atromaculatus, or "SATR") (0.88), Central Stoneroller (Campostoma anomalum, or "CANO") (0.78), Fantail Darter (Etheostoma flabellare, or "EFLA") (0.58), White Sucker (Catostomus commersoni, or "CCOM") (0.39), Striped Shiner (Luxilus chrysocephalus, or "LCHR") (0.28), Northern Hogsucker (Hypentelium nigricans, or "HNIG") (0.23), sculpins (Cottus spp., or "COTT") (0.20) and Snubnose Darter (Etheostoma simoterum, or "ESIM") (0.20). Species with low prevalence were excluded from our species occurrence analyses because low prevalence can bias distribution model performance (van Proosdij et al., 2016).
The $31 \mathrm{IBI}$ metrics (Table 3) included most metrics in the parent IBIs. Two metrics were excluded because data on fish health (i.e., deformities, fin damage, lesions and tumours) and hybridisation were not available for all 83 sites. Computing the IBI metrics required assigning each fish species to a single category for each of the following factors: taxonomic family, trophic guild, reproductive guild, habitat preference, tolerance and native distribution (see Table S1, Supplemental Material). Assignments generally followed those made by the IBI developers, while Jenkins and Burkhead (1994) and the FishTraits database (Frimpong \& Angermeier, 2009) were used as supplemental references to resolve assignment conflicts. The occurrence and count data were then used to compute the IBI response metrics (Table 3).

Boosted regression trees (BRTs) were used to model assemblage composition responses to mining-related variables. BRTs are a nonparametric machine-learning method that extends traditional regression tree models by fitting many decision trees sequentially, while allowing results from previous trees to inform and optimise decision criteria in new trees (Elith et al., 2008). Advantages of BRTs include the abilities to (a) handle binary (e.g., species occurrence), ordinal (e.g., richness) and continuous (e.g., proportional abundance) data, (b) evaluate the relative influence of many predictors, 
(c) reveal nonlinear relationships between response and predictor variables and (d) control for correlations among predictors (Elith et al., 2008).

We ran the BRTs using package dismo in R statistical software (R Core Team, 2018). Binary, ordinal and continuous response metrics were modelled as Bernoulli, Poisson and Gaussian responses respectively. Our default model specifications were bag fraction of 0.50 , learning rate of 0.001 , tree complexity of three and step size of 50. Bag fraction refers to the proportion of observations used in each model iteration (i.e., a cross-validation approach); 0.50 followed recommendations for ecological studies (Elith et al., 2008). Learning rate is the weight applied to each individual model. Tree complexity refers to the number of nodes in a tree; simpler trees reflect more parsimonious models and include fewer predictors. Step size refers to the number of trees competing to reduce deviance at each cycle; trees compete iteratively to optimise the model. In the event that a model did not run, or the model ran but the algorithm did not converge, specifications were adjusted to improve model performance. Aside from model convergence, model performance was evaluated using training and cross-validation (CV) correlations, percentages of deviance explained, and area under the receiver-operating-characteristic curve (AUC). Training and CV deviance explained were computed as the difference between total deviance and residual deviance divided by the total deviance following Elith et al. (2008) and Derville et al. (2016).

\section{3 | RESULTS}

\section{1 | Correlates of the MINE.PC1}

Three strong correlates of mining intensity were identified, including two variables representing site-scale physicochemical conditions and one study-wide spatial-structure variable (Table 3). Site-scale correlates included SPCOND (Figure 3; $r=.53, d f=81$, $p<.0001)$ and COBBLE $(r=.40, d f=81, p=.0002)$. We also observed two weaker site-scale correlates (PEBBLEMC $[r=.34$; $p=.002]$ and WD_RATIO $[r=.31 ; p=.005])$ that did not meet our Bonferroni criterion for significance. The strongest of these relationships was between SPCOND and MINE.PC1 (Figure 1). Other site-scale variables, and all watershed-scale environmental variables, were not correlates of MINE.PC1. Collectively, these results suggest that sites in intensively mined watersheds exhibited elevated conductivity and high percentages of cobble substrates. One of the distance-based Moran's Eigenvector Map metrics (dbMEM1) also was correlated with mining intensity $(r=-.43$, $d f=81, p=.0001)$. This variable represented spatial autocorrelation, in terms of mining intensity, across the east-to-west span of our study area. This result underscores the importance of including spatial eigenvalues in our models so effects of spatial autocorrelation can be assessed directly instead of confounding apparent effects of other environmental variables.

\section{2 | Assemblage composition}

\subsection{1 | Species occurrence}

Occurrence of most fish species was not related to mining intensity. Highly prevalent species tended to be categorised as benthic and tolerant (Table S1, Supplemental Material). Conversely, low prevalence was often associated with nonbenthic, intolerant invertivores. The BRT models ran and converged for three of the nine species-occurrence responses we analysed (CCOM, COTT and EFLA). The COTT model did not initially converge; learning rate (0.0001) and step size (20) were adjusted for this model to achieve convergence. Other occurrence models failed to converge regardless of adjustments, probably due to high (e.g., ROBT) or low prevalence (e.g., ESIM). Only results from convergent models are reported hereafter. The three species-occurrence models were for CCOM, COTT and EFLA (CV AUC: 0.82-0.79) (Table 4). The COTT model performed best, explaining $64.6 \%$ of the deviance in training runs, while the CCOM and EFLA training models both explained $<50 \%$ of the total deviance in their responses. Performance of all models decreased considerably during $\mathrm{CV}$ runs, explaining $31.1 \%$ (COTT), 20.2\% (EFLA) and 17.3\% (CCOM) of the total deviance in responses. CV correlations ranged from 0.52 to 0.56 and showed a trend in performance among occurrence models that was consistent with the percentages of CV deviance explained (Table 4).

Mining-related variables were important predictors of species occurrence for the three convergent models, especially MINE. PC1 and SPCOND as predictors of COTT and EFLA respectively (Figures 4 and 5). MINE.PC1 was the strongest predictor of COTT (relative influence [RI] score of $25.2 \%$ ), exhibiting sharp negative influence on sculpin presence between watersheds with no mining versus low-intensity mining (Figure 4). Other mining-related predictors in the COTT model were far less influential. SPCOND was the strongest predictor of EFLA (RI $=17.4 \%)$, and partial dependence plots suggested a sharp negative decline for Fantail Darter presence between 300 and $500 \mu \mathrm{S} / \mathrm{cm}$ (Figure 4). Fantail Darter occurrence was also negatively influenced by COBBLE $(\mathrm{RI}=5.5 \%)$ and positively influenced by spatial structure (dbMEM1; RI = 7.5\%). The MINE.PC1 gradient itself showed little influence on EFLA ( $R I=1.4 \%)$. While the influence of any mining-related predictors on CCOM was less than that for five other predictors, COBBLE $(R I=5.7 \%)$ and MINE. PC1 $(R I=2.1 \%)$ exhibited slight negative and positive influences on CCOM respectively.

Aside from the strong influence of mining-related predictors, patterns in species occurrences were most commonly driven by descriptors of channel morphology. For instance, SLOPE was the strongest CCOM predictor $(\mathrm{RI}=25.1 \%)$ and partial dependence plots showed White Suckers largely occurred at sites with low stream gradients. Similarly, DEPTH consistently explained some deviance in occurrence, with RIs of $7.4 \%-15.3 \%$. CCOM, COTT and EFLA were largely absent from sites with DEPTH $<10 \mathrm{~cm}$. 
TAB LE 3 Index of Biotic Integrity (IBI) metrics included in boosted regression tree analyses as response variables

\begin{tabular}{|c|c|c|c|c|c|c|}
\hline Code & Metric description & Metric type & $\begin{array}{l}\text { Expected } \\
\text { response }\end{array}$ & $\begin{array}{l}\text { McCormick } \\
\text { et al. (2001) }\end{array}$ & $\begin{array}{l}\text { TVA } \\
\text { IBI }\end{array}$ & $\begin{array}{l}\text { Angermeier } \\
\text { et al. (2000) }\end{array}$ \\
\hline \multicolumn{7}{|c|}{ Richness metrics } \\
\hline MINSP & Number of minnow spp & Taxonomic & - & & & $x$ \\
\hline MNTSP & Number of native minnow spp (without tolerants) & Taxonomic & - & $x$ & & \\
\hline SUNSP & Number of sunfish spp & Taxonomic & - & & & $\mathrm{X}$ \\
\hline SNMSP & $\begin{array}{l}\text { Number of native sunfish spp (without } \\
\text { Micropterus) }\end{array}$ & Taxonomic & - & & $\mathrm{X}$ & \\
\hline DARSP & Number of native darter spp & Taxonomic & - & & $x$ & \\
\hline DOSSP & Number of darter or sculpin spp & Taxonomic & - & & & $x$ \\
\hline LAMSP & Number of late-maturing (age-3+) spp & Reproductive & - & & & $x$ \\
\hline BENSP & Number of benthic spp (without tolerants) & Habitat & - & $\mathrm{x}$ & & \\
\hline POOSP & Number of pool spp & Habitat & + & & $\mathrm{x}$ & \\
\hline \multicolumn{7}{|c|}{ Proportional abundance metrics } \\
\hline DOMPR & Pr. abund. of most-dominant two spp & Taxonomic & + & & $x$ & \\
\hline COTPR & Pr. abund. of sculpins & Taxonomic & - & $x$ & & \\
\hline ALNPR & Pr. abund. of non-natives & Native & + & $x$ & & \\
\hline TOLPR & Pr. abund. of tolerants & Tolerance & + & $x$ & $\mathrm{x}$ & $x$ \\
\hline NBGPR & Pr. abund. of nonbenthic generalist feeders & Trophic & + & & & $x$ \\
\hline BSIPR & Pr. abund. of benthic specialist invertivores & Trophic & - & & & $\mathrm{x}$ \\
\hline PINPR & Pr. abund. of invertivore-piscivores & Trophic & - & $\mathrm{x}$ & & \\
\hline PISPR & Pr. abund. of piscivores & Trophic & - & & $x$ & \\
\hline SLIPR & Pr. abund. of simple lithophils & Reproductive & - & $x$ & $x$ & \\
\hline SLTPR & Pr. abund. of simple lithophils (without tolerants) & Reproductive & - & & & $\mathrm{x}$ \\
\hline NNLPR & Pr. abund. of nonsimple nonlithophils & Reproductive & + & & & $\mathrm{x}$ \\
\hline \multicolumn{7}{|c|}{ Density metric } \\
\hline $\mathrm{CATCH}$ & Total catch rate (mean number $/ 300 \mathrm{ft}^{2}\left[28.7 \mathrm{~m}^{2}\right]$ ) & Density & - & & $x$ & \\
\hline
\end{tabular}

Note: We included 31 metrics used in three Mid-Atlantic Highland region IBIs developed by Angermeier et al. (2000), McCormick et al. (2001) and Tennessee Valley Authority (TVA, 2005). "X" indicates that a metric is included in the authors' IBI. "spp" = species. "Pr. abund." = proportional abundance. "Expected response" refers to a metric's response to mining disturbance in a formerly unmined watershed.

\subsection{2 | IBI metrics}

Most (28/31) BRT models describing responses of IBI metrics converged (Table 4). The SUNSP and OMHPR models did not initially converge; results for these two models are based on subsequent specifications that achieved convergence (learning rate $=0.0001$; step size $=20$ ). Models were nonconvergent due to the low prevalence (e.g., ALNSP) or low variance (e.g., PISPR) of response variables. Only results from convergent models are reported hereafter.

Models exhibited a wide range of performance, explaining $3.6 \%-80.2 \%$ of the total deviance in their response variables (Table 4). All models explained low percentages of CV deviance (0.4\%-47.5\%). The final models for TOTSP, DARSP, DOSSP, NATSP, 


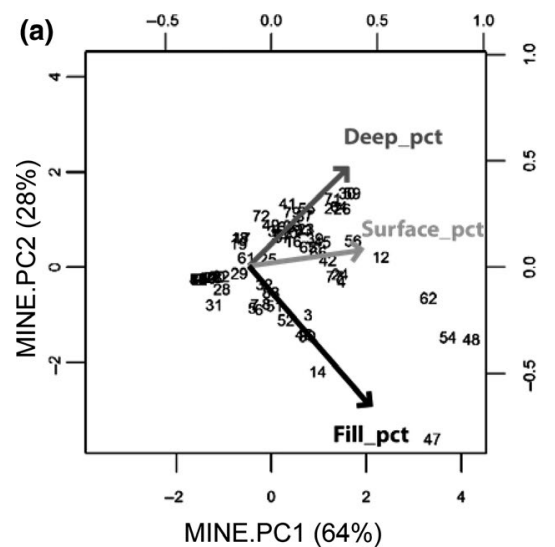

(b)

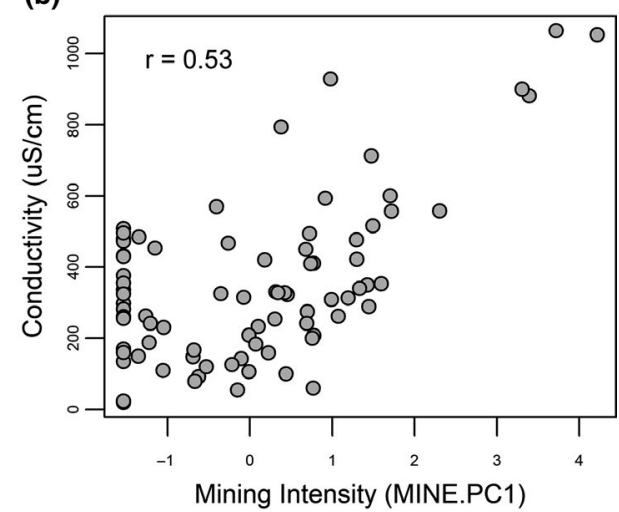

FIGURE 3 (a) Biplot (left plot) of first (MINE.PC1) and second (MINE.PC2) axes from a principal components analysis (PCA) of percentage watershed areas of active surface mines ("Surface_pct"; light grey vector), active deep mines ("Deep_pct"; dark grey vector) and valley fills ("Fill_pct"; black vector) among the 83 study watersheds. Numbers inside the biplot represent selected watershed identifiers. Vector lengths represent how strongly the individual mining characteristics influenced the principal components (i.e., loading); variable loadings are indicated on the top and right axes. Principal component scores are on the bottom and left axes. (b) Scatterplot (right plot) of the significant relationship between conductivity and our mining-intensity gradient, MINE.PC1, among sites. The plot shows raw conductivity values for ease of interpretation, but the Pearson's product-moment correlation was examined with conductivity square-root transformed $(r=0.53$, $d f=81, p=.00003)$

BENSP, LAMSP, POOSP, DOMPR, TOLPR and MACPR performed best; each model explained $\geq 50 \%$ of the deviance during training runs, and $\geq 25 \%$ of the deviance during CV. Models for three richness metrics (TOTSP, NATSP, BENSP) exhibited strong correlations between observed and CV-fitted values ( $\geq 0.70$ ).

Mining-related variables, including MINE.PC1, strongly influenced IBI metrics; RI scores ranged from $0.2 \%$ to $35.0 \%$ among models (Figure 5). RI scores for MINE.PC1 were $>10 \%$ on three proportional abundance metrics (COTPR [21.7\%], OMHPR [28.3\%] and CARPR [11.3\%]), but it was not the strongest predictor of any IBI metric. Taxonomic (MINSP, DOSSP, COTPR), trophic (CARPR, INVPR) and reproductive (NNLPR) metrics showed negative nonlinear responses to MINE.PC1. Partial dependence plots suggested these responses vary in change-point and magnitude. Sculpin proportional abundance (COTPR) decreased sharply between unmined and low-mining watersheds (Figure 4), similar to the sculpin occurrence response. MINSP (RI = 5.7\%), DOSSP (RI = 3.4\%), CARPR, INVPR (RI = 5.6\%) and NNLPR (RI = 6.2\%) decreased sharply in watersheds with MINE.PC1 values between 0 and 1, suggesting greater tolerance to mining relative to sculpins (Figure 5). MINE.PC1 was also positively related to two trophic metrics, OMHPR and MACPR ( $R \mathrm{I}=4.8 \%$ ).

Model results also suggest the site-scale physicochemical variables associated with mining intensity were important predictors of numerous IBI metrics, which were most responsive to SPCOND $(\mathrm{RI}=0.1 \%-14.2 \%)$ and $\operatorname{COBBLE}(\mathrm{RI}=1.2 \%-20.8 \%)$ (Figure 4$)$. SPCOND had $>10 \%$ RI on trophic (OMHPR, CARPR, INVPR, SINPR, BSIPR) and reproductive (NNLPR) metrics measured as proportional abundance (Figure 5). SPCOND was negatively related to all but OMHPR, and these five negative responses shared a sharp decline at 300-500 $\mu \mathrm{S} / \mathrm{cm}$ (Figure 5). Conversely, OMHPR, MACPR (RI = 5.4\%) and $\mathrm{CATCH}(\mathrm{RI}=2.2 \%)$ responded positively to SPCOND, with declines at approximately $300-600 \mu \mathrm{S} / \mathrm{cm}$ (Figure 4). COBBLE had $>10 \%$ influence on taxonomic (MINSP, MNTS, DOMPR), habitat use (POOSP), trophic (OMHPR, CARPR, INVPR, PISPR) and reproductive (SLTPR) metrics and was the most influential predictor for three of these (OMHPR, CARPR, SLTPR) (Figure 5). Overall, COBBLE showed greater RI values across all response metrics than did MINE.PC1 or SPCOND (Figure 5).

Considering the models collectively, mining-related predictors were secondary in relative influence on IBI metrics to three stream-size covariates-mean maximum depth (DEPTH), mean wetted width (WIDTH) and watershed area (WSAREA) (Figure 6). At least one of these covariates was the most influential predictor in 22 of the 28 models; their RI ranges among models were $1.7 \%-53.1 \%, 1.1 \%-19.0 \%$ and $2.1 \%-29.0 \%$ respectively (Figure 6). DEPTH was the most influential predictor in 16 models. Streamsize covariates were generally positively related to IBI metrics, commonly exhibiting sharp responses at approximately $12 \mathrm{~cm}$ DEPTH, 2-4 m WIDTH, and 3.0-4.5 km² WSAREA. However, TOLPR, NBGPR, PINPR and CATCH were exceptions and exhibited some negative responses at 12-25 cm DEPTH, 2-4 $\mathrm{m}$ WIDTH and $10-20 \mathrm{~km}^{2}$ WSAREA.

\section{DISCUSSION}

We documented strong ties among extent of coal mining in a watershed, instream physicochemical features and fish assemblage structure in Appalachian headwaters. Two site-scale physicochemical measures (conductivity and predominance of cobble) were positively correlated with our mining-intensity gradient and important predictors of fish assemblage patterns. Several measures of species occurrence, taxonomic diversity and composition of trophic and 
reproductive guilds responded strongly to mining intensity and its instream physicochemical correlates. Expectedly and most prominently, elevated conductivity in mined watersheds appeared to limit invertivores and piscivores, but benefit omnivore-herbivores. Fine-sedimentation was, unexpectedly, not a prominent stressor, and relationships between habitat and reproductive guilds were counterintuitive. Our results are consistent with studies highlighting the influence of mining-impacted stream production on biotic assemblages (Cianciolo et al., 2020; Northington et al., 2011; Presser, 2013; Voss \& Bernhardt, 2017; Whitmore et al., 2018) and emphasise the complexity of mining impacts manifest through novel species- and trait-based sensitivities paired with water and habitat quality alterations.

\subsection{Physicochemical correlates of mining intensity}

Our mining-intensity gradient (MINE.PC1), synthesising extents of underground mines, surface mines and valley fills, was associated with instream conditions. MINE.PC1's positive correlation with conductivity is consistent with numerous studies of mined Appalachian watersheds (Cormier, Wilkes, et al., 2013; Daniel et al., 2015; Griffith et al., 2012; Nippgen et al., 2017; Petty et al., 2010; USEPA, 2011; Zipper et al., 2016), but its positive correlation with percentage of substrate as cobble was counter to our expectations. Instead, we expected excess fine sediment to be a primary mining-related stressor. Concerns about fine-sediment loading have shaped mining-mitigation strategies, which focus on restoring natural hydrologic regimes and limiting sediment delivery from surface mines and valley fills (Zipper et al., 2011). However, our correlates of sedimentation (e.g., percentage of substrate $\geq 75 \%$ embedded, percentage of substrate particles $\leq 8 \mathrm{~mm}$ ) were not correlated with MINE.PC1.

This pattern-reported elsewhere (Nuttle et al., 2017; Touysinhthiphonexay \& Gardner, 1984)-has at least two plausible explanations. First, our watersheds with steep topography (coarser substrates) may coincidentally have been mined more intensively than less rugged watersheds and percentage slope and relief (meters) rasters from widely used datasets such as NHDPlusV2 could be overlaid on coal mining extents to examine these patterns further. While a formal analysis is outside of the study scope herein, a preliminary correlation analysis suggests our watersheds with higher minimum slopes and summed relief values were high mining intensity catchments. Second, a predominance of cobble may reflect an increase in flood intensity, perhaps exacerbated by loss of forest cover (Temple, 1997). Mining commonly reduces water-infiltration rates, and the extra runoff gives mined streams greater capacity to flush fine sediments from their beds (Townsend et al., 2009). Our findings suggest that the primary mining-related stressor in our streams is not fine sediment, but more likely altered water chemistry. Other studies have shown that mining affects instream concentrations of major ions, metals, and trace elements more than it affects benthic habitat quality (Griffith et al., 2012; Pond et al., 2008). Even so, our finding of simultaneous effects on water and habitat quality exemplifies the complexity of pathways through which mining may affect biotic assemblages.

\section{2 | Responses of fish assemblages to mining}

Coal mining impacts stream-fish assemblages via direct and indirect pathways (Figure 1). Our models revealed that both landscape and instream correlates of mining explain some variation in fish assemblages, even while accounting for confounding factors such as stream size. We documented increasingly simplified assemblages with increasing mining intensity. A few tolerant omnivore-herbivore species (i.e., Western Blacknose Dace and Central Stoneroller) predominated in intensively mined watersheds but darters and sculpins were largely absent, and invertivores, piscivores, simple lithophils and nonsimple nonlithophils were all rare. Shifts in conductivity and substrate composition seem to be closely linked to the assemblage responses we observed, as illustrated by apparent sharp declines in individual species occurrences (Fantail Darter), trophic guilds that rely on secondary production for food (invertivores), and some reproductive guilds (simple lithophils and nonsimple nonlithophils). The specific pathways leading to these biotic outcomes remain unclear but offer promising topics for future research.

Two benthic invertivores exhibited distinctive responses along our mining-intensity gradient. Fantail Darter occurrence was strongly related to conductivity but not to MINE.PC1; they exhibited a sharp negative response at $300-500 \mu \mathrm{S} / \mathrm{cm}$. This is a lower range of conductivity associated with decreasing probability of observing Fantail Darter compared with the range (300-3,000 $\mu \mathrm{S} / \mathrm{cm})$ reported by USEPA (2016b) and Griffith et al. (2018) and used to derive the value below which $95 \%$ of Fantail Darter observations in Appalachia occurred $(<3,266 \mu \mathrm{S} / \mathrm{cm})$. Our results showed local population reductions at conductivities about one-tenth of that. Other darters are also sensitive to coal mining and elevated conductivity (Griffith et al., 2018; Hitt et al., 2016; Hopkins \& Roush, 2013; USEPA, 2016b), including three species (Emerald Darter Etheostoma baileyi, Stripetail Darter Etheostoma kennicotti, Kentucky Arrow Darter Etheostoma spilotum) with documented conductivity thresholds similar to our Fantail Darter observations. Although Fantail Darters are often regarded as environmentally tolerant (Jenkins \& Burkhead, 1994), our findings suggest they may be indicators of elevated conductivity in the upper Tennessee River basin.

In contrast, Cottus occurrence and proportional abundance exhibited sharp negative relationships with MINE.PC1 but not with conductivity. Since our mining-intensity gradient incorporated three classes of mining activity that collectively and simultaneously influence many abiotic metrics, the mechanisms causing the sculpin responses remain unclear. Sculpins are sensitive to several physicochemical impacts of mining, including elevated conductivity (Griffith et al., 2018; USEPA, 2016b) and metals (Allert et al., 2009; Besser et al., 2007). However, the extirpation concentrations varied from 518 to 2,046 among four species of Cottus (Griffith et al., 2018). The high physiological sensitivity of sculpins to elevated concentrations 
TAB LE 4 Performance summary of the 29 convergent boosted regression tree models of species occurrences and IBI metrics

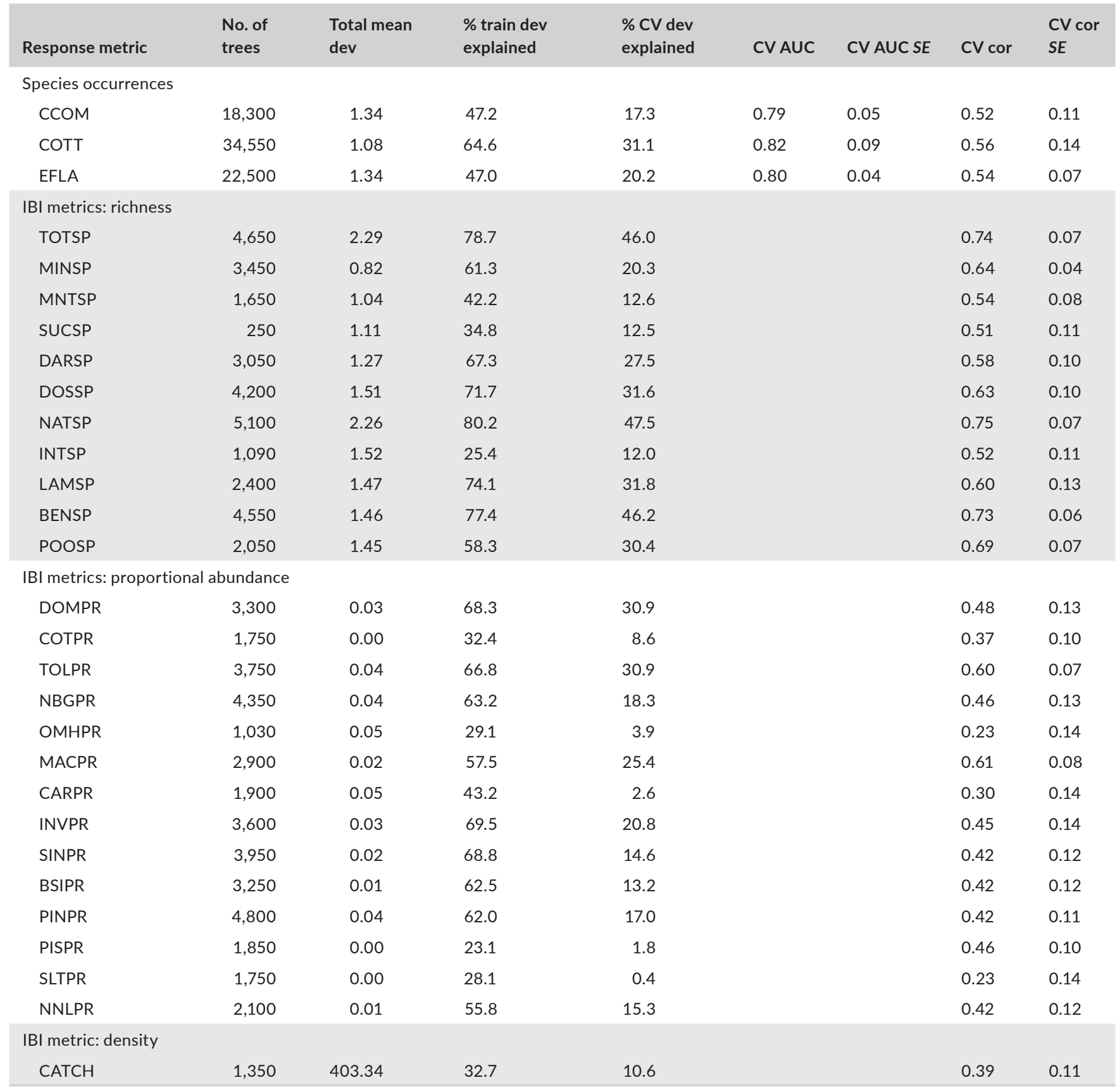

Note: Diagnostics for each model include the number (No.) of trees grown in model runs, total mean deviance (dev) in response variables, mean residual dev from training (train) and cross-validated (CV) model runs, standard error (SE) of the CV resid dev, and percentage (\%) of mean dev and CV dev explained. For Bernoulli response models, training and CV area under the receiver-operating-characteristic curve (AUC) values are reported, along with the SE of CV AUCs. For Gaussian response models, training and CV correlation (cor) plus CV cor SE are reported. Species abbreviations: $\mathrm{CCOM}=$ Catostomus commersoni, COTT = Cottus spp., EFLA = Etheostoma flabellare. IBI metric labels are explained in Table 3.

of metals associated with mining could explain why our sculpin responses aligned more closely with MINE.PC1 than conductivity (Allert et al., 2009; Besser et al., 2007), but this explanation remains uncertain without sampling additional water chemistry variables. Our results highlight the need to more closely examine how water chemistry, beyond conductivity, may influence fish assemblages in mining-impacted streams. The role of traits (e.g., invertivory) associated with these responses to MINE.PC1 and mining correlates are discussed further below, and must be considered in future examinations of these species-level observations.

Certain trophic traits were associated with gradients in water chemistry (conductivity) and physical habitat (predominance of cobble). Our results corroborate studies describing simultaneous increases in omnivore-herbivore proportional abundance and decreases in invertivores and piscivores (Daniel et al., 2015). Invertivores were most strongly negatively tied to conductivity and 
(a)

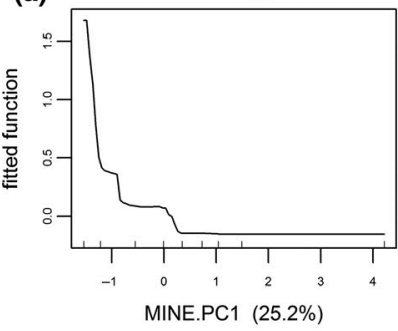

(b) Etheostoma flabellare

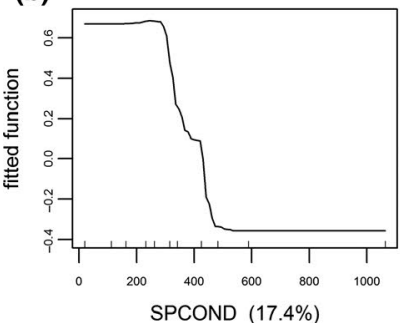

(c)

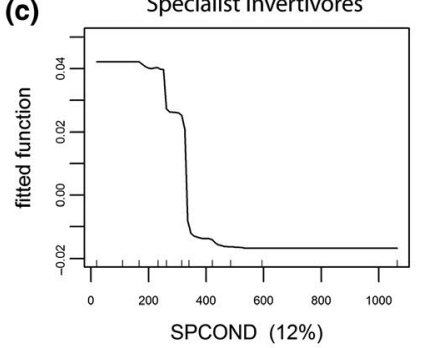

(d)

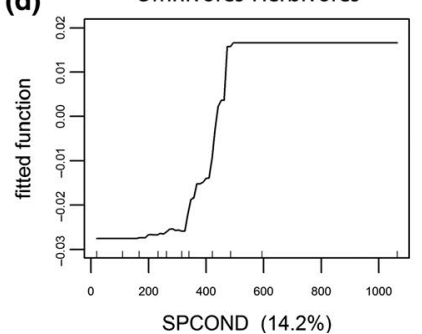

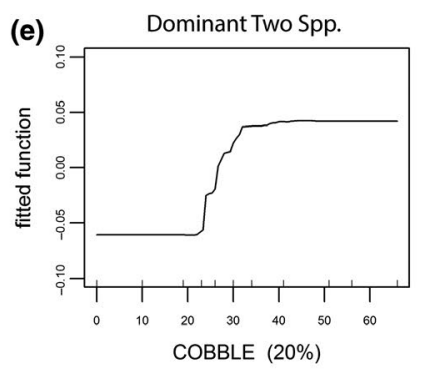
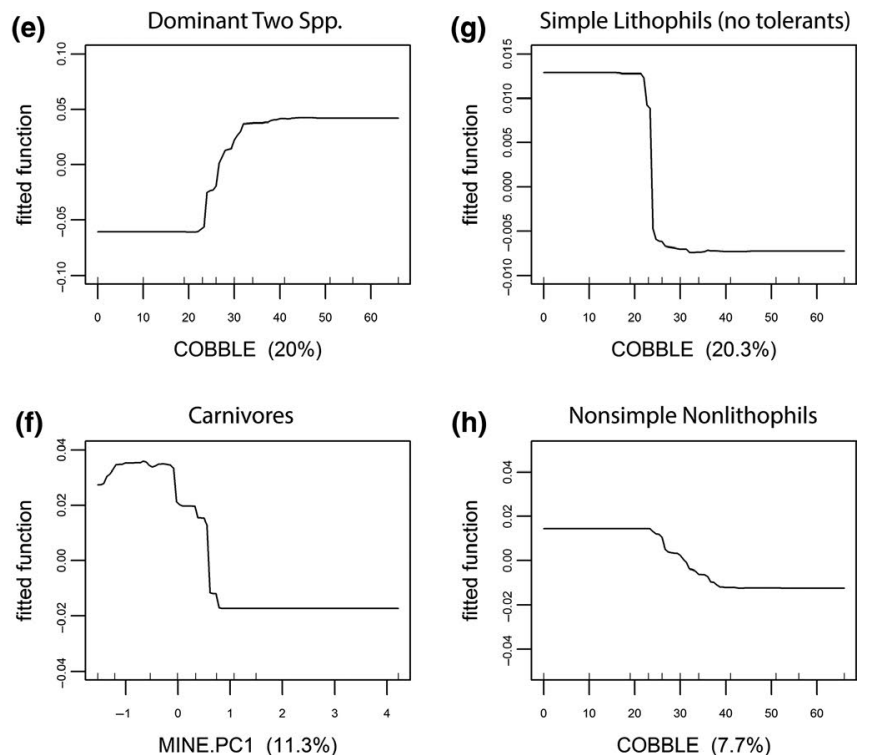

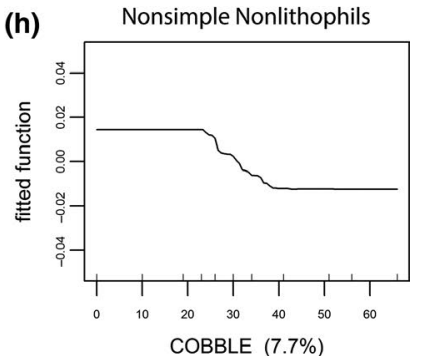

FIGURE 4 Partial dependence plots of eight metrics most responsive to mining-related variables. The first column shows responses in (a) sculpins Cottus spp. (COTT) and (b) Fantail Darter Etheostoma flabellare (EFLA) presence to MINE.PC1 and SPCOND respectively. SPCOND was strongly negatively related to EFLA presence, with a threshold occurring near $300-500 \mu \mathrm{S} / \mathrm{cm}$. The second column shows responses to SPCOND by (c) specialist invertivores and (d) omnivore-herbivores. The third column shows responses in proportional abundances of (e) the two most-dominant species (spp.) per site and (f) carnivores (invertivore-piscivores and piscivores combined), to COBBLE and MINE.PC1 respectively. Counts of Western Blacknose Dace strongly positively and negatively influenced these two responses respectively. The fourth column shows responses in proportional abundances of $(\mathrm{g})$ simple lithophils (excluding tolerant species) and (h) nonsimple nonlithophils, both negatively related to presence of COBBLE, which increased with increasing mining intensity. Predictor variable abbreviations (defined in Table 2) on $\mathrm{x}$-axes are accompanied by relative influence (RI) percentages

MINE.PC1. Past studies have inferred that invertivore responses to mining were tied to limited prey availability (Daniel et al., 2015; Hitt \& Chambers, 2014; Stair et al., 1984) or contaminated prey (e.g., bioaccumulation of Se) (Arnold et al., 2014; Whitmore et al., 2018). Coal mining commonly reduces abundance and diversity of macroinvertebrates (Cormier, Suter, et al., 2013; Drover et al., 2020; Freund \& Petty, 2007; Pond et al., 2008; Vander Vorste et al., 2019; Voss \& Bernhardt, 2017), and elevated conductivity limits macroinvertebrate survival and reproduction (Armstead et al., 2016; USEPA, 2011). In addition, coal mining promotes bioaccumulation of contaminants by macroinvertebrates and fishes (Arnold et al., 2014; Whitmore et al., 2018), and contaminated prey may impair the fitness of invertivores and piscivores inhabiting mining-impacted streams (Arnold et al., 2014; Presser \& Luoma, 2010; USEPA, 2016a, 2016b). Overall, the shifts in trophic composition observed by us and others along gradients of mining intensity support the hypothesis that mining fundamentally alters stream productivity in ways that limit fish species feeding at upper trophic levels.

Our finding that omnivore-herbivore abundance responds positively to mining intensity has multiple explanations. First, it may reflect a general tolerance to mining-related stressors (e.g., chemistry, sediment). For example, omnivore-herbivores' reliance on primary production in their diet may reduce their susceptibility to impaired fitness via bioaccumulation or biomagnification of contaminants (Presser, 2013; Presser \& Luoma, 2010; Whitmore et al., 2018). Second, relative increases in omnivore-herbivores may be indirect responses to shifts in autochthonous versus allochthonous production since water chemistry, riparian forest cover and/or macroinvertebrate assemblages change along gradients of mining intensity (Daniel et al., 2015; Drover et al., 2020; Voss \& Bernhardt, 2017). Validating either explanation requires additional analyses of species-specific sensitivities and system-wide production dynamics.

The overall trophic trends we observed are plausibly linked to all three components of stream habitats and resources affected by coal mining (i.e., water chemistry, physical habitat, food resources; Figure 1), which in turn have multiple modes of action for potentially affecting individual fitness. For instance, shifting availability and/ or contamination of foods associated with (a) mining intensity, (b) coarser substrates or (c) elevated conductivity can affect fish stress, metabolism, development, behaviour and migration (Presser, 2013; Whitmore et al., 2018). The relative importance of these mechanisms to the biotic impacts of coal mining in general remain rich topics for future research.

The predominance of some fish reproductive traits also varied with mining intensity but not necessarily as expected. Previous work demonstrated that simple lithophils respond negatively to increasing mining (Daniel et al., 2015; Hitt \& Chambers, 2014). Thus, we expected this trait to respond negatively to increases in fine sedimentation (MacDonald \& McDonald, 1987). Instead, we saw similar responses by two traits reflecting different habitat requirements. Simple lithophils (without tolerants; SLTPR) and nonsimple nonlithophils (NNLPR) both responded negatively to increases in cobble and conductivity (Figures 4 and 5). Further, the negative response to elevated conductivity occurred at a similar range for both traits. The 

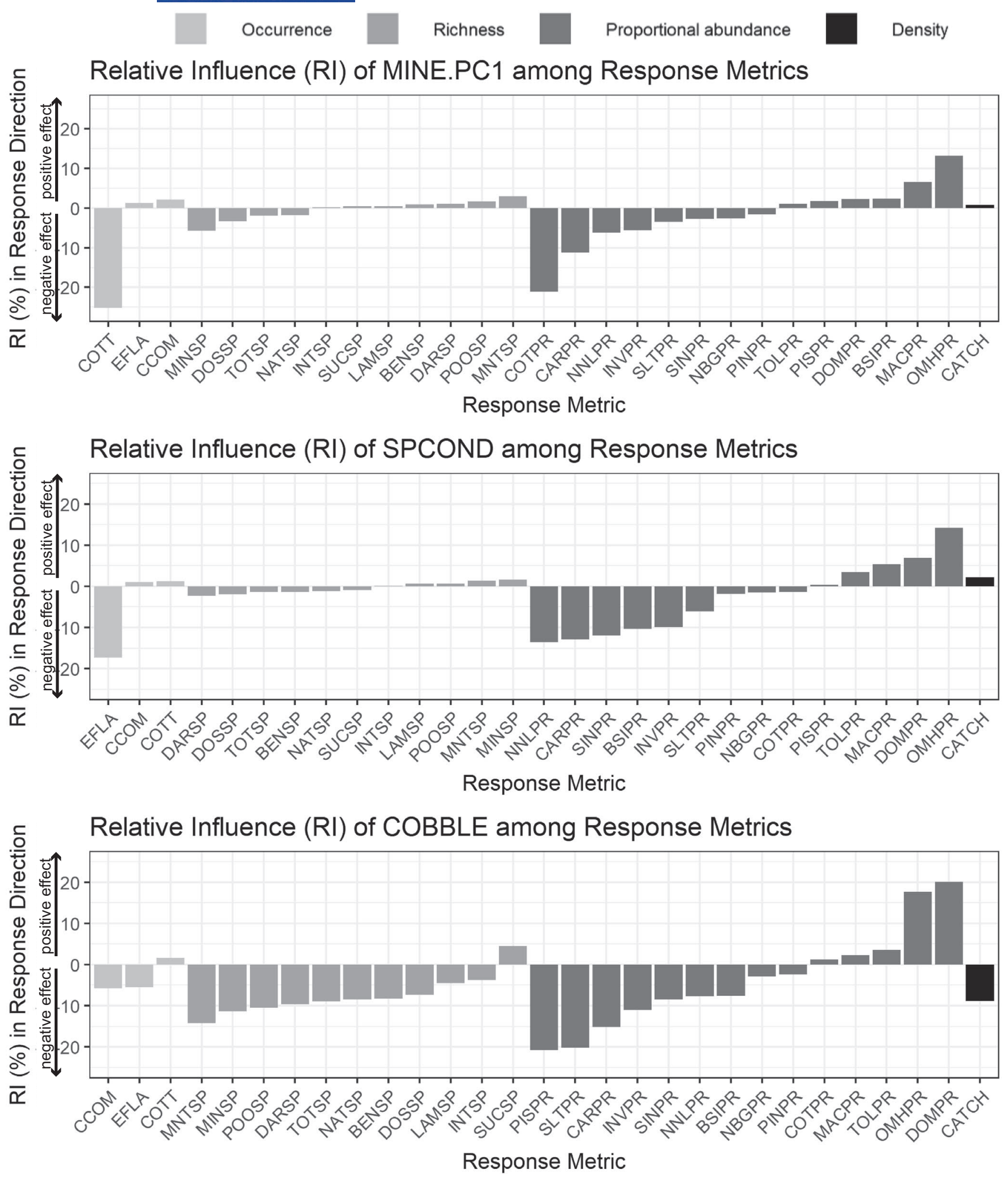

FIGURE 5 Relative influence (RI) percentages of the three most influential mining-related predictors of fish assemblage responses: MINE.PC1 (mining-intensity gradient), SPCOND (conductivity $[\mu \mathrm{S} / \mathrm{cm}]$ ) and COBBLE (substrate composition as cobble [\%]). Response metric abbreviations on the $\mathrm{x}$-axis are defined in Table 3. Response metrics on each barplot are ordered first by metric class (species occurrence [light grey], IBI richness [grey], IBI proportional abundance [dark grey] and IBI density [black]), then by magnitude and direction of RI score (-100 to 100) 


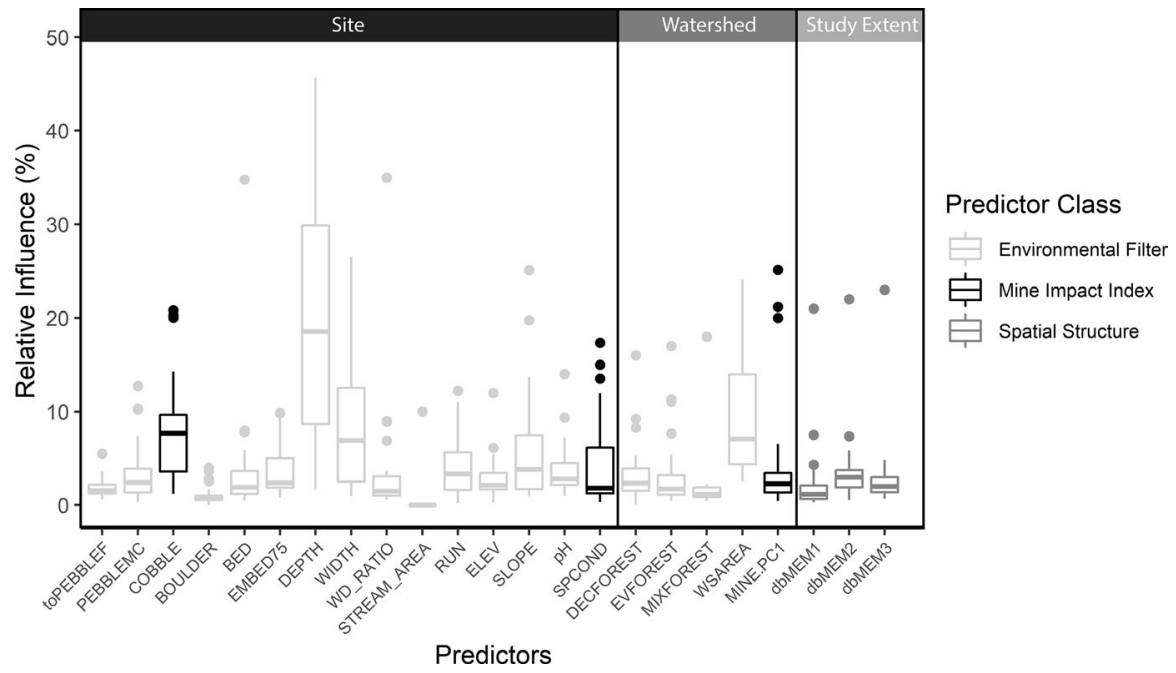

FIGURE 6 Relative influence (RI) of the 23 predictors on the 29 responses metrics in convergent models of species occurrence, species richness, proportional abundances and density. Boxplots are coloured by the predictor class, according to whether they represented a natural environmental ("Environmental Filter"; light grey), mining intensity ("Mine Impact Index"; black) or spatial structure ("Spatial Structure"; dark grey) gradient in boosted regression trees. Boxplots are ordered left-to-right on the $x$-axis by site-scale, watershed-scale and study extent predictors, indicated by coloured and labelled bars at the top of the plot. Predictor variable abbreviations on the $x$-axis are defined in Table 2

negative responses of both traits to cobble abundance are puzzling because NNLPR species nest in cobbles, and excess fine sediment (which fills cobble interstices) generally leads to reductions in SLTPR species (Kemp et al., 2011). Our findings imply that shifts in the prevalence of reproductive traits along our gradient of mining intensity are driven more by variation in conductivity than by variation in fine sediment. Significant knowledge gaps remain regarding how mining-related shifts in physical habitat (e.g., relative bed stability) and water chemistry (e.g., major ion concentrations) affect reproductive success of stream fishes.

\section{3 | Implications for bioassessment in Central Appalachian coalfield streams}

Understanding the pathways whereby anthropogenic activities impact stream-fish assemblages is critical to assessing and managing those impacts (Matthaei \& Lange, 2016; Norton \& Schofield, 2017). However, continued documentation of impact pathways and improvements in study design can help in developing a general synthesis of coal mining impacts in Central Appalachia. Improvements in bioassessment and monitoring programmes could include further consideration of pre-mining conditions, careful consideration of the appropriate spatiotemporal resolutions to use in analyses, broader focus beyond physicochemical stressors, and use of calibrated assessment tools (Giam et al., 2018; Hitt \& Chambers, 2014; Palmer \& Hondula, 2014). Design features that improved on previous studies of mining impacts and facilitated novel insights from our analyses included a focus on headwater streams, spatial replication of study sites and analyses of both abiotic and biotic indicators. Despite knowledge gaps, plausible pathways can be represented in heuristic conceptual models, which provide scaffolding for organising current knowledge and testing hypotheses related to impact pathways (Norton \& Schofield, 2017). The structure of such models can evolve as new knowledge emerges, which may in turn affect choices of measured indicators and analytical approaches, as well as the eventual conclusions reached (Roberts et al., 2016). Our coarse-grained conceptual model (Figure 1) helped us organise current knowledge of how coal mining may influence stream fishes and informed our choices of which physicochemical and biological attributes to measure.

Even if mechanisms remain poorly understood, the degree of system-level impact imposed by coal mining can be measured by monitoring appropriate endpoints. Coal mining alters a large array of physicochemical variables (Griffith et al., 2012), some of which profoundly affect stream biota at individual, population or assemblage levels of organisation. Although the specific mix of potential physicochemical stressors (and their relative importance) may vary by region and by the extent, age and type of mining (Daniel et al., 2015; Nuttle et al., 2017; Petty et al., 2010), these stressors are commonly tied to sediment composition and water chemistry, especially conductivity (Figure 1). We documented marked shifts in fish assemblage composition at 300-500 $\mu \mathrm{S} / \mathrm{cm}$ conductivity (Figures 4 and 5), with Fantail Darter exhibiting greater sensitivity than reported elsewhere (Griffith et al., 2018; USEPA, 2016b). Our findings are consistent with water quality criteria proposed to protect macroinvertebrates $(300 \mu \mathrm{S} / \mathrm{cm})$ and fishes $(509 \mu \mathrm{S} / \mathrm{cm})$ in Central Appalachian streams (USEPA, 2011; Cormier, Suter, et al., 2013; USEPA, 2016b: Appendix G; Griffith et al., 2018).

We also saw fish responses that were not clearly linked to any physicochemical attribute we measured. For example, some IBI metrics (e.g., proportional abundance of sculpins) responded strongly 
to MINE.PC1, but not to conductivity; this may be due to an unmeasured variable related to mining (e.g., trace elements). Overall, the patterns we observed warrant further examination, with an eye toward developing regionally applicable fish-based metrics that can help assess the degree of impacts from coal mining. Identifying a suite of mining-sensitive biotic metrics-representing multiple taxa and levels of ecological organisation-could enhance the reliability and interpretability of assessments of streams potentially impacted by coal mining (Kimmel \& Argent, 2010).

Current assessments of coal-mining impacts on Central Appalachian streams are based on a limited view of stream health. In Virginia and West Virginia, surface-mining permits require permittees to provide instream water quality measurements and macroinvertebrate-based bioassessments prior to initiating mining (baseline), while the permit is active, and for 3-5 years postreclamation (VDMME, 2019; WVEP, 2012). Bioassessments derived from a multi-metric stream condition index $(\mathrm{SCl})$ are compared to state-specific (but not disturbance-specific) thresholds for biological impairment. If the $\mathrm{SCl}$ score indicates impairment due to mining activity, the permittee may be required to implement additional control measures or management practices, to improve the biological condition of the stream. Incorporating biotic responses specific to mining into the interpretation and application of bioassessments would likely increase the specificity of management requirements and success in improving biological conditions. Fish-based bioassessments could provide additional information to help assess the cumulative impacts of multiple mining operations in a watershed and prescribe management practices and control measures at a broader spatial scale (e.g., across multiple permittees). Moreover, all of these assessment tools could be improved by a) advances in knowledge of impact pathways and b) careful selection of additional physicochemical and biological indicators with empirically demonstrated links to those pathways.

Multi-metric indices such as macroinvertebrate- and fish-based IBIs are widely used to assess anthropogenic impacts in streams and other ecosystems (Angermeier \& Karr, 2019). Many US states even incorporate such IBIs into their water quality standards (O'Brien et al., 2016). Individual IBI metrics are chosen from suites of plausible metrics based on their empirically verified responses along region-specific gradients of anthropogenic impact (Angermeier et al., 2000; Smogor \& Angermeier, 1999). Overall IBI scores (usually computed for a given site) reflect cumulative anthropogenic impacts in an ecosystem, with the collective metrics providing more information about ecological conditions than simple physicochemical measures. Most IBIs include metrics that reflect species' foraging and reproduction traits, which in turn influence fitness. Responses by these metrics can be especially insightful in understanding the pathways through which anthropogenic activities affect biotic assemblages (Teresa \& Casatti, 2017).

Most fish-based IBIs are designed to assess a wide range of anthropogenic impacts, and such IBIs have been used to assess mining impacts (Freund \& Petty, 2007; McCormick et al., 1994; Stoertz et al., 2002; USFS, 2017). However, other IBIs are focused on impacts of specific activities such as water abstraction (Benejam et al., 2010), PCB contamination (Simon et al., 2013), and timber harvest (da Silveira Prudente et al., 2018). Although the metrics we analysed were developed to detect impacts generally, many-including richness, trophic and reproductive metrics-clearly responded to mining impacts (Table 4). This implies that some of these could be assembled into an effective fish-based IBI focused on assessing impacts of coal mining across Central Appalachia. Developing such a tool would require (a) additional testing of existing and potential metrics, (b) expanding the spatiotemporal scope of metric evaluation to include all of Central Appalachia across many years, (c) narrowing the list of mining-sensitive metrics to those to be included in an IBI and (d) calibrating scores for component metrics so all scores perform concordantly along a region-wide gradient of mining intensity. We believe a mining-centric IBI could enhance current bioassessments of streams in the Central Appalachian coalfields, thereby informing regulatory and restoration success.

\section{ACKNOWLEDGEMENTS}

The Appalachian Research Institute for Environmental Sciences and the Virginia Center for Coal and Energy Research supported this research. D.J. Orth was supported in part by the U.S. Department of Agriculture through the National Institute of Food and Agriculture Program and Virginia Tech. Contributions from Brandon Plunkett and Fleming Bors-Koefoed as our field sampling technicians are appreciated. Michael Moore, Tony Timpano, and Kriddie Whitmore provided spatial data and field notes from previous studies that benefitted site selection. Valerie Holland helped enter data. We thank Tony Timpano and Xingli Giam for helpful comments on the manuscript. This work was carried out under the auspices of Institutional Animal Care and Use Committee Protocols 15-093 and 16-044 at Virginia Tech. The Virginia Cooperative Fish and Wildlife Research Unit is jointly sponsored by U.S. Geological Survey, Virginia Tech, Virginia Department of Wildlife Resources, and Wildlife Management Institute. Any use of trade, firm or product names is for descriptive purposes only and does not imply endorsement by the U.S. Government.

\section{CONFLICT OF INTEREST}

We have no conflicts of interest to declare.

\section{DATA AVAILABILITY STATEMENT}

Data used in our analyses come from a combination of publicly available databases and direct field observations. The publicly available repositories include geospatial resources managed by federal agencies (Multi-Resolution Land Characteristics Consortium <https:// www.mrlc.org> [30-m 2011 National Land Cover Database], NHDPlusV2 <https://www.epa.gov/waterdata/get-nhdplus-national-hydrography-dataset-plus-data> [National Hydrography Dataset, National Elevation Dataset, Watershed Boundary Dataset]) and Virginia Department of Mines, Minerals, and Energy (Mapping and Resource Center <https://www.dmme.virginia.gov/dmlr/Mappi ngLandingPage.shtml $>$ [surface and underground mine permits and extents, valley fill extents]). Our direct field observations, and those from Moore et al. (2017), of physicochemical stream condition and 
fish assemblage have not been made available in a public repository at this time; however, these data are available and our R programming scripts are available upon request (contact corresponding author: zpmartin@vt.edu).

\section{ORCID}

Zachary P. Martin (iD https://orcid.org/0000-0001-9385-8601

Paul L. Angermeier (iD https://orcid.org/0000-0003-2864-170X

Donald J. Orth (iD https://orcid.org/0000-0002-9236-0147

\section{REFERENCES}

Allert, A. L., Fairchild, J. F., Schmitt, C. J., Besser, J. M., Brumbaugh, W. G. \& Olson, S. J. (2009). Effects of mining-derived metals on riffle-dwelling fishes in southeast Missouri. Ecotoxicology and Environmental Safety, 72, 1642-1651.

Angermeier, P. L., \& Karr, J. R. (2019). Ecological health indicators. In B. D. Fath (Ed.), Encyclopedia of ecology (Vol. 1, 2nd ed.). Elsevier.

Angermeier, P. L., Smogor, R. A., \& Stauffer, J. R. (2000). Regional frameworks and candidate metrics for assessing biotic integrity in mid-Atlantic highland streams. Transactions of the American Fisheries Society, 129, 926-981. https://doi.org/10.1577/1548-8659(2000)129<0962:RFACMF $>2.3 . \mathrm{CO} ; 2$

Angermeier, P. L., \& Winston, M. R. (1999). Characterizing fish community diversity across Virginia landscapes: Prerequisite for conservation. Ecological Applications, 9(1), 335-349.

Armstead, M. Y., Bitzer-Creathers, L., \& Wilson, M. (2016). The effects of elevated specific conductivity on the chronic toxicity of mining influenced streams using Ceriodaphnia dubia. PLoS One, 11(11), e0165683

Arnold, M. C., Lindberg, T. T., Liu, Y. T., Porter, K. A., Hsu-Kim, H., Hinton, D. E., \& DiGiulio, R. T. (2014). Bioaccumulation and speciation of selenium in fish and insects collected from a mountaintop removal coal mining-impacted stream in West Virginia. Ecotoxicology, 23, 929938. https://doi.org/10.1007/s10646-014-1236-4

Benejam, L., Angermeier, P. L., Munne, A., \& Garcia-Berthou, E. (2010). Assessing effects of water abstraction on fish assemblages in Mediterranean streams. Freshwater Biology, 55, 628-642. https://doi. org/10.1111/j.1365-2427.2009.02299.x

Bernhardt, E. S., \& Palmer, M. A. (2011). The environmental costs of mountaintop mining valley fill operations for aquatic ecosystems of the Central Appalachians. Annals of the New York Academy of Sciences, 1223, 39-57. https://doi.org/10.1111/j.1749-6632.2011.05986.x

Besser, J. M., Mebane, C. A., Mount, D. R., Ivey, C. D., Kunz, J. L., Greer, I. E., May, T. W., \& Ingersoll, C. G. (2007). Sensitivity of mottled sculpins (Cottus bairdi) and rainbow trout (Onchorhynchus mykiss) to acute and chronic toxicity of cadmium, copper, and zinc. Environmental Toxicology and Chemistry, 26(8), 1657-1665. https:// doi.org/10.1897/06-571R.1

Bunte, K., \& Abt, S. R. (2001). Sampling surface and subsurface particle-size distributions in wadable gravel- and cobble-bed streams for analyses in sediment transport, hydraulics, and streambed monitoring. General technical report. RMRS-GTR-74 (428 p.). : U.S. Department of Agriculture, Forest Service, Rocky Mountain Research Station.

Cianciolo, T. R., McLaughlin, D. L., Zipper, C. E., Timpano, A. J., Soucek, D. J., Whitmore, K. M., \& Schoenholtz, S. H. (2020). Selenium bioaccumulation across trophic levels and along a longitudinal gradient in headwater streams. Environmental Toxicology and Chemistry, 39(3), 692-704.

Colin N., Villéger S., Wilkes M., de Sostoa A., Maceda-Veiga A. (2018). Functional diversity measures revealed impacts of non-native species and habitat degradation on species-poor freshwater fish assemblages. Science of The Total Environment, 625, 861-871. http://dx.doi. org/10.1016/j.scitotenv.2017.12.316
Cormier, S. M., Suter, G. W. II, Zheng, L., \& Pond, G. J. (2013). Assessing causation of the extirpation of stream macroinvertebrates by a mixture of ions. Environmental Toxicology and Chemistry, 32(2), 277-287.

Cormier, S. M., Wilkes, S. P., \& Zheng, L. (2013). Relationship of land use and elevated ionic strength in Appalachian watersheds. Environmental Toxicology and Chemistry, 32(2), 296-303.

da Silveira Prudente, B., Pompeu, P. S., \& Montag, L. (2018). Using multimetric indices to assess the effect of reduced impact logging on ecological integrity of Amazonian streams. Ecological Indicators, 91, 315-323.

Daniel, W. M., Infante, D. M., Hughes, R. M., Tsang, Y., Esselmann, P. C., Wieferich, D., \& Taylor, W. W. (2015). Characterizing coal and mineral mines as a regional source of stress to stream fish assemblages. Ecological Indicators, 50, 50-61.

Derville S., Constantine R., Baker C. S., Oremus M., Torres L. G. (2016). Environmental correlates of nearshore habitat distribution by the Critically Endangered Maūi dolphin. Marine Ecology Progress Series, 551, 261-275. http://dx.doi.org/10.3354/meps11736

Drover, D. R., Schoenholz, S. H., Soucek, D. J., \& Zipper, C. E. (2020). Multiple stressors influence macroinvertebrate communities in central Appalachian coalfield streams. Hydrobiologia, 847(1), 191-205.

Elith, J., Leathwick, J. R., \& Hastie, T. (2008). A working guide to boosted regression trees. Journal of Animal Ecology, 77, 802-813.

Elkins D., Sweat S. C., Kuhajda B. R., George A. L., Hill K. S., Wenger S. J. (2019). Illuminating hotspots of imperiled aquatic biodiversity in the southeastern US. Global Ecology and Conservation, 19, e00654. http://dx.doi.org/10.1016/j.gecco.2019.e00654

Evans, D. M., Zipper, C. E., Donovan, P. F., \& Daniels, W. L. (2014). Longterm trends in specific conductance in waters discharged by coalmine valley fills in central Appalachia, USA. Journal of the American Water Resources Association, 50, 1449-1460.

Ferreri, C. P., Stauffer, J. R., \& Stecko, T. D. (2004). Evaluating impacts of mountain top removal/valley fill coal mining on stream fish populations. In Paper presented at the Proceedings of the American Society of Mining and Reclamation (pp. 576-592).

Fitzpatrick, F. A., Waite, I. R., D'Arconte, P. J., Meador, M. R., Maupin, M. A., \& Gurtz, M. E. (1998). Revised methods for characterizing stream habitat in the NAWQA Program. (Water-Resources Investigations Report 98-4052). U.S. Geological Survey.

Freund, J. G., \& Petty, J. T. (2007). Response of fish and macroinvertebrate bioassessment indices to water chemistry in a mined Appalachian watershed. Environmental Assessment, 39, 707-720. https://doi.org/10.1007/s00267-005-0116-3

Frimpong, E. A., \& Angermeier, P. L. (2009). FishTraits: A database of ecological and life-history traits of freshwater fishes of the United States. Fisheries, 34(10), 487-495. https://doi. org/10.1577/1548-8446-34.10.487

Frimpong, E. A., \& Angermeier, P. L. (2010). Trait-based approaches in the analysis of stream fish communities. American Fisheries Society Symposium, 73, 109-136.

Giam, X., Olden, J. D., \& Simberloff, D. (2018). Impact of coal mining on stream biodiversity in the US and its regulatory implications. Nature Sustainability, 1, 176-183. https://doi.org/10.1038/s4189 3-018-0048-6

Griffith, M. B., Norton, S. B., Alexander, L. C., Pollard, A. I., \& LeDuc, S. D. (2012). The effects of mountaintop mines and valley fills on the physicochemical quality of stream ecosystems in the central Appalachians: A review. Science of the Total Environment, 417-418, 1-12. https://doi.org/10.1016/j.scitotenv.2011.12.042

Griffith, M. B., Zheng, L., \& Cormier, S. M. (2018). Using extirpation to evaluate ionic tolerance of freshwater fish. Environmental Toxicology and Chemistry, 37(3), 871-883. https://doi.org/10.1002/ etc. 4022 
Hafs, A. W., Horn, C. D., Mazik, P. M., \& Hartman, K. J. (2010). Influences of acid mine drainage and thermal enrichment on stream fish reproduction and larval survival. Northeastern Naturalist, 17(4), 575-592. https://doi.org/10.1656/045.017.0405

Hitt, N. P., \& Chambers, D. B. (2014). Temporal changes in taxonomic and functional diversity of fish assemblages downstream from mountaintop mining. Freshwater Science, 33(3), 915-926. https://doi. org/10.1086/676997

Hitt, N. P., Floyd, M., Compton, M., \& McDonald, K. (2016). Threshold responses of blackside dace (Chrosomus cumberlandensis) and Kentucky arrow darter (Etheostoma spilotum) to stream conductivity. Southeastern Naturalist, 15(1), 41-60.

Holm, J., Palace, V. P., Wautier, K., Evans, R. E., Baron, C. L., Podernski, C., \& Sterling, G. (2003). An assessment of the development and survival of wild rainbow trout (Oncorhynchus mykiss) and brook trout (Salvelinus fontinalis) exposed to elevated selenium in an area of active coal mining. Paper presented at the The Big Fish Bang, Proceedings of the 26th annual larval fish conference.

Hopkins, R. L., \& Roush, J. C. (2013). Effects of mountaintop mining on fish distributions in central Appalachia. Ecology of Freshwater Fish, 22, 578-586. https://doi.org/10.1111/eff.12061

Jenkins, R. E., \& Burkhead, N. M. (1994). Freshwater fishes of Virginia. Bethesda, Maryland.

Kemp, P., Sear, D., Collins, A., Naden, P., \& Jones, I. (2011). The impacts of fine sediment on riverine fish. Hydrological Processes, 25, 1800-1821. https://doi.org/10.1002/hyp.7940

Kimmel, W. G., \& Argent, D. G. (2010). Stream fish community responses to a gradient of specific conductance. Water, Air, and Soil Pollution, 206, 49-56. https://doi.org/10.1007/s11270-009-0085-x

MacDonald, D. D., \& McDonald, L. E. (1987). The influence of surface coal mining on potential salmonid spawning habitat in the Fording River, British Columbia. Water Pollution Research Journal of Canada, 22(4), 584-595. https://doi.org/10.2166/wqrj.1987.047

Martin, Z. P., Ciparis, S., Angermeier, P. L., \& Orth, D. J. (2018). Impact of mining effluent on fish populations. Final report. Virginia Center for Coal and Energy Research.

Matter, W. J., \& Ney, J. J. (1981). The impact of surface mine reclamation on headwater streams in Southwest Virginia. Hydrobiologia, 78, 63-71. https://doi.org/10.1007/BF00011942

Matthaei, C. D., \& Lange, K. (2016). Multiple stressor effects on freshwater fish: A review and meta-analysis. In G. P. Gloss, M. Krkosek, \& J. D. Olden (Eds.), Conservation of freshwater fishes (pp. 178-199). Cambridge University Press.

McCormick, F. H., Hill, B. H., Parrish, L. P., \& Willingham, W. T. (1994). Mining impacts on fish assemblages in the Eagle and Arkansas Rivers. Colorado. Freshwater Ecology, 9(3), 175-179. https://doi. org/10.1080/02705060.1994.9664884

McCormick, F. H., Hughes, R. M., Kaufmann, P., Peck, D. V., Stoddard, J. L., \& Herlihy, A. L. (2001). Development of an index of biotic integrity for the Mid-Atlantic Highlands region. Transactions of the American Fisheries Society, 130, 857-877. https://doi. org/10.1577/1548-8659(2001)130<0857:DOAIOB>2.0.CO;2

McKay, L., Bondelid, T., Dewald, T., Johnston, J., Moore, R., \& Rea, A. (2012). NHDPlus version 2: User guide. US Environmental Protection Agency.

Moore, M. J., Hallerman, E. M., \& Orth, D. J. (2017). Densities and population sizes of Clinch Dace Chrosomus sp. cf. saylori in the Upper Clinch River Basin in Virginia. Copeia, 105(1), 92-99.

Mouillot, D., Graham, N. A. J., Villeger, S., Mason, N. W. H., \& Bellwood, D. R. (2013). A functional approach reveals community responses to disturbances. Trends in Ecology and Evolution, 28(3), 167-177. https:// doi.org/10.1016/j.tree.2012.10.004

Nippgen, F., Ross, M. R. V., Bernhardt, E. S., \& McGlynn, B. L. (2017). Creating a more perennial problem? Mountaintop removal coal mining enhances and sustains saline baseflows of Appalachian watersheds. Environmental Science and Technology, 51, 8324-8334. https://doi.org/10.1021/acs.est.7b02288

Northington, R. M., Benfield, E. F., Schoenholtz, S. H., Timpano, A. J., Webster, J. R., \& Zipper, C. E. (2011). An assessment of structural attributes and ecosystem function in restored Virginia coalfield streams. Hydrobiologia, 671, 51-63. https://doi.org/10.1007/s1075 0-011-0703-7

Norton, S. B., \& Schofield, K. A. (2017). Conceptual model diagrams as evidence scaffolds for environmental assessment and management. Freshwater Science, 36(1), 231-239. https://doi. org/10.1086/690296

Nuttle, T., Logan, M. N., Parise, D. J., Foltz, D. A., Silvis, J. M., \& Haibach, M. R. (2017). Restoration of macroinvertebrates, fish, and habitats in streams following mining subsidence: Replicated analysis across 18 mitigation sites. Restoration Ecology, 25(5), 820-831. https://doi. org/10.1111/rec.12502

O'Brien, A., Townsend, K., Hale, R., Sharley, D., \& Pettigrove, V. (2016). How is ecosystem health defined and measured? A critical review of freshwater and estuarine studies. Ecological Indicators, 69, 722-729. https://doi.org/10.1016/j.ecolind.2016.05.004

Palmer, M. A., \& Hondula, K. L. (2014). Restoration as mitigation: Analysis of stream mitigation for coal mining impacts in Southern Appalachia. Environmental Science and Toxicology, 48, 10552-10560. https://doi. org/10.1021/es503052f

Petty, J. T., Fulton, J. B., Strager, M. P., Merovich, G. T., Stiles, J. M., \& Ziemkiewicz, P. F. (2010). Landscape indicators and thresholds of stream ecological impairment in an intensively mined Appalachian watershed. Journal of the North American Benthological Society, 29, 1292-1309. https://doi.org/10.1899/09-149.1

Pond, G. W., Passmore, M. E., Borsuk, F. A., Reynolds, L., \& Rose, C. J. (2008). Downstream effects of mountaintop coal mining: Comparing biological conditions using family- and genus-level macroinvertebrate bioassessment tools. Journal of the North American Benthological Society, 27, 717-737. https://doi.org/10.1899/08-015.1

Presser, T. S. (2013). Selenium in ecosystems within the mountaintop coal mining and valley-fill region of southern West Virginia-Assessment and ecosystem-scale modeling. (USGS, Professional Paper 1803).

Presser, T. S., \& Luoma, S. N. (2010). A methodology for ecosystem-scale modeling of selenium. Integrated Environmental Assessment and Management, 6(4), 685-710. https://doi.org/10.1002/ieam.101

$R$ Core Team (2018). R: A language and environment for statistical computing. R Foundation for Statistical Computing. Retrieved from http:// www.R-project.org/

Roberts, J. H., Anderson, G. B., \& Angermeier, P. L. (2016). A long-term study of ecological impacts of river channelization on the population of an endangered fish: Lessons learned for assessment and restoration. Water, 8(240), 1-38. https://doi.org/10.3390/w8060240

Ross, M. R. V., McGlynn, B. L., \& Bernhardt, E. S. (2016). Deep impact: Effects of mountaintop mining of surface topography, bedrock structure, and downstream waters. Environmental Science and Technology, 50(4), 2064-2074.

Schorr, M. S., \& Backer, J. C. (2006). Localized effects of coal mine drainage on fish assemblages in a Cumberland Plateau stream in Tennessee. Journal of Freshwater Ecology, 21, 17-24. https://doi. org/10.1080/02705060.2006.9664091

Simon, T. P., Morris, C. C., \& Sparks, D. W. (2013). Patterns in stream fish assemblage structure and function associated with a PCB gradient. Environmental Contamination and Toxicology, 65(2), 286-299. https:// doi.org/10.1007/s00244-013-9889-1

Smith, R. K., Freeman, P. L., Higgins, J. V., Wheaton, K. S., Fitzhugh, T. W., Ernstrom, K. J., \& Das, A. A. (2002). Priority areas for conservation action: A biodiversity assessment of the southeastern United States. The Nature Conservancy, 1, 8-35.

Smogor, R. A., \& Angermeier, P. L. (1999). Relations between fish metrics and measures of anthropogenic disturbance in three $\mathrm{IBI}$ regions in 
Virginia. In T. P. Simon (Ed.), Assessing the sustainability and biological integrity of water resources using fish communities (pp. 858-910). CRC Press Inc.

Stair, D. M., Tolbert, V. R., \& Vaughn, G. L. (1984). Comparison of growth, population structure, and food of the creek chub Semotilus atromaculatus in undisturbed and surface-mining disturbed streams in Tennessee. Environmental Pollution, 35, 331-343. https://doi. org/10.1016/0143-1471(84)90078-3

Stanfield, L. W., Lester, N. P., \& Petreman, I. C. (2013). Optimal effort intensity in backpack electrofishing surveys. North American Journal of Fisheries Management, 33(2), 277-286. https://doi. org/10.1080/02755947.2012.758200

Stoertz, M. W., Bourne, H., Knotts, C., \& White, M. M. (2002). The effects of isolation and acid mine drainage on fish and macroinvertebrate communities of Monday Creek, Ohio, USA. Mine Water and the Environment, 21(2), 60-72. https://doi.org/10.1007/s102300200021

Temple, A. J. (1997). The effects of coal mining on sedimentation and fish assemblages in the Powell River, Virginia (unpublished doctoral dissertation). Virginia Tech.

Teresa, F. B., \& Casatti, L. (2017). Trait-based metrics as bioindicators: Responses of stream fish assemblages to a gradient of environmental degradation. Ecological Indicators, 75, 249-258. https://doi. org/10.1016/j.ecolind.2016.12.041

Timpano, A. J., Schoenholtz, S. H., Soucek, D. J., \& Zipper, C. E. (2015). Salinity as a limiting factor for biological condition in mining-influenced Central Appalachian headwater streams. Journal of American Water Resources Association, 51(1), 240-250. https://doi.org/10.1111/jawr.12247

Touysinhthiphonexay, K. C. N., \& Gardner, T. W. (1984). Threshold response of small streams to surface coal mining, bituminous coal fields, central Pennsylvania. Earth Surface Processes and Landforms, 9, 43-58. https://doi.org/10.1002/esp.3290090106

Townsend, P. A., Helmers, D. P., Kingdon, C. C., McNeil, B. E., de Beurs, K. M., \& Eshleman, K. N. (2009). Changes in the extent of surface mining and reclaimation in Central Appalachians deteted using 19762006 Landsat time series. Remote Sensing of Environment, 113, 62-72.

TVA (Tennessee Valley Authority) (2005). DRAFT: Protocol for conducting an index of biotic integrity biological assessment, updated 2005. Knoxville, Tennessee.

USEPA (United States Environmental Protection Agency) (2002). Clinch and Powell Valley watershed ecological risk assessment. (EPA/600/R-01/050). National Center for Environmental Assessment.

USEPA (United States Environmental Protection Agency) (2005). Mountaintop mining/valley fills in appalachia: Final programmatic environmental impact statement. (EPA 9-03-R-05002). Philadelphia, Pennsylvania.

USEPA (United States Environmental Protection Agency) (2011). A fieldbased aquatic life benchmark for conductivity in Central Appalachian streams (Final Report). EPA-600th-R-10-023F. Office of Water.

USEPA (United States Environmental Protection Agency) (2016a). Aquatic life ambient water quality criterion for selenium - Freshwater 2016 (EPA 822-R-16-006). : Office of Water.

USEPA (United States Environmental Protection Agency) (2016b). Public Review Draft: Field-based methods for developing aquatic life criteria for specific conductivity. (EPA 822-R-07-010). : Office of Water.

USFS (United States Department of Agriculture, Forest Service) (2017). Index of biotic integrity for mine influenced streams; Redbird District Daniel Boone National Forest, 2015. Southern Research Station, Center for Aquatic Technology Transfer.

USGS (United States Geological Survey) (2000). Effects of coal-mine drainage on stream water quality in the Allegheny and Monongahela River basins-Sulfate transport and trends. (USGS, Water Resources Investigations Report 99-4208). Lemoyne, Pennsylvania.
USGS (United States Geological Survey) (2001). Reconnaissance of stream geomorphology, low streamflow, and stream temperature in the mountaintop coal-mining region, southern West Virginia, 1999-2000. (USGS, Water Resources Investigations Report 01-4092). Charleston, West Virginia.

van Proosdij, A. S. J., Sosef, M. S. M., Wieringa, J. J., \& Raes, N. (2016). Minimum required number of specimen records to develop accurate species distribution models. Ecography, 39, 542-552.

Vander Vorste, R., Timpano, A. J., Cappellin, C., Badgley, B. D., Zipper, C. E., \& Schoenholtz, S. H. (2019). Microbial and macroinvertebrate communities, but not leaf litter decomposition, change along a mining-induced salinity gradient. Freshwater Biology, 2019, 1-14.

VDMME (Virginia Department of Mines, Minerals, and Energy) (2015). Mapping and resource center [online database]. From Division of Mined Land Reclamation. Retrieved from dmme.virgnia.gov

VDMME (Virginia Department of Mines, Minerals, and Energy) (2019). Retrieved from https://www.dmme.virginia.gov/dmlr/DmlrOperat orMemos.shtml

Voss, K. A., \& Bernhardt, E. S. (2017). Effects of mountaintop removal coal mining on the diversity and secondary productivity of Appalachian rivers. Limnology and Oceanography, 62, 1754-1770. https://doi. org/10.1002/Ino.10531

Weber-Scannell, P. K., \& Duffy, L. K. (2006). Effects of total dissolved solids on aquatic organisms: A review of literature and recommendations for salmonid species. American Journal of Environmental Sciences, 3(1), 1-6.

Whitacre, H. W., Roper, B. B., \& Kershner, J. L. (2007). A comparison of protocols and observer precision for measuring physical stream attributes. Journal of the American Water Resources Association, 43(4), 923-937. https://doi.org/10.1111/j.1752-1688.2007.00074.x

Whitmore, K. M., Schoenholtz, S. H., Soucek, D. J., Hopkins, W. A., \& Zipper, C. E. (2018). Selenium dynamics in headwater streams of the Central Appalachian coalfield. Environmental Toxicology and Chemistry, 37(10), 2714-2726. https://doi.org/10.1002/etc.4245

WVEP (West Virginia Department of Environmental Protection) (2012). Permitting guidance for surface coal mining operations to protect West Virginia's Narrative Water Quality Standards, 47 C.S.R. 2 § 3.2.e and 3.2.i. Retrieved from https://dep.wv.gov/pio

Zipper, C. E., Burger, J. A., Skousen, J. G., Angel, P. N., Barton, C. D., Davis, V., \& Franklin, J. A. (2011). Restoring forests and associated ecosystem services on Appalachian coal surface mines. Environmental Management, 47, 751-765. https://doi.org/10.1007/ s00267-011-9670-z

Zipper, C. E., Donovan, P. F., Jones, J. W., Li, J., Price, J. E., \& Stewart, R. E. (2016). Spatial and temporal relationships among watershed mining, water quality, and freshwater mussel status in an eastern USA river. Science of the Total Environment, 541, 603-615. https://doi. org/10.1016/j.scitotenv.2015.09.104

\section{SUPPORTING INFORMATION}

Additional supporting information may be found online in the Supporting Information section.

How to cite this article: Martin ZP, Angermeier PL, Ciparis S, Orth DJ. Coal-mining intensity influences species and trait distributions of stream fishes in two Central Appalachian watersheds. Ecol Freshw Fish. 2020;00:1-19. https://doi. org/10.1111/eff.12588 